(C)2018, Elsevier. Licensed under the Creative Commons Attribution-NonCommercial-NoDerivatives 4.0 International http://creativecommons.org/about/downloads 


\title{
Eccentric Low-Velocity Impact On Fiber-Metal Laminates Under In-Plane Loading Using Unified Zigzag Theory
}

\author{
Mehran Ghalami-Choobar ${ }^{1}$, Gholamhossein Liaghat ${ }^{1,2, *}$, Mojtaba Sadighi $^{3}$, Hamed Ahmadi $^{1}$ \\ ${ }^{1}$ Department of Mechanical Engineering, Tarbiat Modares University (TMU), Tehran, Iran \\ ${ }^{2}$ School of Mechanical \& Aerospace Engineering, Kingston University, London, England \\ ${ }^{3}$ Mechanical Engineering Faculty, Amirkabir University of Technology, Tehran, Iran
}

\begin{abstract}
This paper investigates the eccentric low-velocity impact of Fiber metal laminates (FMLs) subjected to spherical projectile using a unified Zig-Zag plate theory. The presented zig-zag plate theory enforces transverse shear stress continuity through the thickness and can be reduced to conventional plate theories using appropriate shape function. The governing equations and suitable boundary conditions are obtained using the principle of minimum total potenital energy. RungeKutta method is employed to solve initial value problem resulted by the method of Ritz. The present model is validated by comparison and good agreement between its results and those of reports in open literature. Influence of various specifications of impact phenomenon such as laminate thickness, projectile radius, projectile velocity, in-plane load and eccentricity parameter is examined on deflection and contact force time history. The obtained results indicate that continuity of transverse shear stress is required to achieve accurate contact force even for moderately thin FMLs.
\end{abstract}

Keywords: Zig-Zag theories; Fiber metal laminates; Interlaminar shear stress continuity, Equivalent Single Layer; Low-velocity impact

\footnotetext{
*Faculty of Mechanical Engineering, Tarbiat Modares University, Jalal Ale Ahmad Highway, Tehran, Iran P.O.B: $14115-111$.

E-Mail:ghlia530@modares.ac.ir, g.liaghat@kingston.ac.uk
} 


\section{Introduction}

With a growing demand for lightweight structures in aerospace industry, an enormous amount of current researches targeted in development of new composite structures. The recent works focused on Fiber metal laminates (FMLs) which are built up of thin metallic sheets and fiber reinforced composites (Fig. 1) [1,2]. FMLs combine impact resistance and easy repair of metals and superior strength of stiffness of composites $[3,4]$.

Fokker Aerostructure of Netherlands discovered that bonded laminates prevent the rapid crack growth compared to the monolithic materials in 1950 [5]. However, after the second worldwide war, the first mechanical test was performed around 1970. The first optimized FML called ARALL (Aramid Reinforced ALuminium Laminate) manufactured by Delft University in 1982 [6]. ARALL was employed in C17 cargo doors. GLARE (GLAss REinforced aluminum laminate) was developed in 1987 because ARALLs suffers from inadequate compression properties. Utilizing GLARE in upper fuselage structure of Airbus A380 caused saving nearly $794 \mathrm{~kg}$ gross weight [5].

Primary structure requires an accurate prediction of stress field which can be achieved by considering the non-classical effects such as transverse shear and normal deflection [7]. Equivalent Single Layers (ESL) theories such as First-order Shear Deformation Theory (FSDT), High-order Shear Deformation Theory (HSDT) and Advanced High Order Theories offer a simple solution to thin and moderately thick laminates[8]. However, these theories suffer from some drawbacks in modeling high transverse anisotropic laminate. On the other hand, Layer-Wise theory (LWT) provides high accurate predictions, whereas it becomes computationally expensive in case of laminates with a large number of layers [9].

Zig-Zag Theories (ZZT) offer a simple way to consider shear deformation in the framework of ESL theories. Due to capture transverse anisotropy, slope of in-plane displacement through the thickness varies as shown in Fig. 2 which is called Zig-Zag phenomenon [10]. Carrera developed a unified theory including ESL, LW and ZZ effects as a special case. The finite element matrices derived in a unified manner and vast numerical examples have been given $[11,12]$. Brischetto et al employed Murakami's ZZ function (MZZF) to analysis sandwich panels [13]. Gherlone et al [10] examined the mixed formulation of MZZF in comparison with displacement-based MZZF, RZT and Timoshenko beam. They showed RZT is more accurate for arbitrary lay-ups by considering the ZZ effects. Groh and Weaver [7] presented displacement-based and mixed formulation based 
on Reddy shape- function and MZZF. Also, they developed a unified general theory through Hellinger-Reissner mixed formulation to consider non-classical effect in analysis of highly heterogeneous multilayers $[14,15]$.

Aerospace structures may encounter low-velocity impact caused by sources such as tool drop, runway stones, etc. According to the literature, the analytical modeling procedure of impact can be classified into three types [16]: spring-mass models [17,18], energy balance models [19,20], structural models based on plate theories(including 1-tem Ritz method [21] and N-term Ritz method [22]).

To the best of our knowledge, most researchers investigated FMLs numerically or experimentally. A few research works focused on analytical models to predict impact response of FMLs. Vlot indicated that the impact model required depends on the impact regime [23]. Tsamasphyros and Bikakis studied the low-velocity response circular GLARE FML using 1-term Ritz method. They predicted the first failure(fiber fracture) for studied circular plates [24]. Bikakis investigated the low-velocity impact of circular GLARE FMLs using linearized spring-mass model. He presented an analytical expression to predict the impact load, position and velocity time history and compared the predicted results with those of experiments [25]. Morinière et al developed a progressive quasi-static model to predict dynamic response of GLARE subjected to low-velocity impact. They indicated aluminum layers absorbed $90 \%$ of the total energy absorbed by the FMLs during impact [26]. Zarei et al investigated dynamic response of FMLs subjected to low-velocity impact based on HSDT. The effect of projectile velocity, projectile radius and thermal environment was studied in detail [27].

In the present work, the eccentric low-velocity impact of FMLs subject to spherical projectile is investigated. Hertz law of contact is employed to consider the nonlinear phenomena of contact. A ZZ plate theory is presented based on Groh and Weaver's [7] theory for the beam structure. Governing equations and suitable boundary conditions are obtained using the principle of minim total energy. Runge-Kutta method is employed to solve initial value problem resulted by the method of Ritz. Influence of various specifications of impact phenomenon is examined on deflection and contact force time history. 


\section{Governing equations}

In the present study, a rectangular FML plate is formulated within the framework of Zig-Zag theory (ZZT) as shown in Fig. 3. According to ZZT, transverse shear stresses of $\mathrm{k}^{\text {th }}$ layer at any point $(\mathrm{x}, \mathrm{y}, \mathrm{z})$ for a symmetric laminate can be expressed as based on [7]

$$
\left.\tau_{x z}^{(k)}(x, y, z)=\left[G_{x}\left\{A_{x}^{(k)}+m_{x}^{(k)}\left(\frac{d \varnothing(z)}{d z}-1\right)\right)\right\}\right] \bar{\gamma}_{x z}(x, y)
$$

and

$$
\left.\tau_{y z}^{(k)}(x, y, z)=\left[G_{y}\left\{A_{y}^{(k)}+m_{y}^{(k)}\left(\frac{d \varnothing(z)}{d z}-1\right)\right)\right\} \bar{\gamma}_{y z}\right](x, y)
$$

where $\bar{\gamma}_{x z}(x, y)$ and $\bar{\gamma}_{y z}(x, y)$ are transverse shear stress in xz-plane and transverse shear stress in yz-plane, respectively. A posteriori shape function $\emptyset(z)$ is considered to include shear stress variation through the thickness within framework of the various plate deformation theories (See Table 1).

In Eq. 1, the modification factors, $m_{x}^{(k)}$ and $m_{y}^{(k)}$ can be expressed as

$$
\begin{aligned}
& m_{x}^{(k)}=e_{x}^{(k)}\left(g_{x}^{(k)}+\frac{1}{g_{x}^{(k)}}-1\right) \\
& m_{y}^{(k)}=e_{y}^{(k)}\left(g_{y}^{(k)}+\frac{1}{g_{y}^{(k)}}-1\right)
\end{aligned}
$$

where $e_{x}^{(k)}$ and $e_{x}^{(k)}$ are defined as

$$
\begin{aligned}
& e_{x}^{(k)}=\frac{\bar{Q}_{x x}{ }^{(k)}}{E_{x}}, e_{y}^{(k)}=\frac{\bar{Q}_{y y}{ }^{(k)}}{E_{y}} \\
& E_{x}=1 / h \sum_{k^{k}=1}^{N} t^{(k)} \bar{Q}_{x x}{ }^{(k)}, E_{y}=1 / h \sum_{k^{\prime}=1}^{N} t^{(k)} \bar{Q}_{y y}{ }^{(k)}
\end{aligned}
$$

and $g_{x}^{(k)}$ and $g_{y}^{(k)}$ are defined as

$$
g_{x}^{(k)}=G_{x} / G_{x z}^{(k)}
$$




$$
G_{x}=\left[\frac{1}{h} \sum_{k=1}^{N} \frac{t^{(k)} G_{x}^{(k)}}{{ }^{-1}}\right.
$$

and

$$
\begin{aligned}
& g_{y}^{(k)}=G_{y} / G_{x z}^{(k)} \\
& G_{y}=\left[\frac{1}{h} \sum_{k=1}^{N} \frac{t^{(k)}}{G_{x}^{(k)}}\right]^{-1}
\end{aligned}
$$

The present ZZT utilized a piece-wise continues stress field offers capability to enforce Interlaminar continuity(IC) for transverse stresses through the thickness. In Eq 1, shear stress layer-wise constants in xz- plane, $A_{x}^{(k)}$, are determined as

$$
\begin{aligned}
& \tau_{x z}^{(1)}\left(z_{0}\right)=0 \\
& A_{x}^{(1)}=-m_{x}^{(1)}\left(\frac{d \emptyset}{d z}-1\right)
\end{aligned}
$$

and

$$
\begin{aligned}
& \tau_{x z}^{(k)}=\tau_{x z}^{(k+1)} \\
& A_{x}^{(k+1)}=A_{x}^{(k)}+\left(m_{x}^{(k)}-m_{x}^{(k+1)}\right)\left(\frac{d \emptyset}{d z}-1\right)
\end{aligned}
$$

and shear stress layer-wise constants in yz- plane, $A_{y}^{(k)}$

$$
\begin{aligned}
& \tau_{y z}^{(1)}\left(z_{0}\right)=0 \\
& A_{y}^{(1)}=-m_{y}^{(1)}\left(\frac{d \emptyset}{d z}-1\right)
\end{aligned}
$$

and

$$
\begin{aligned}
& \tau_{y z}^{(k)}=\tau_{y z}^{(k+1)} \\
& A_{y}^{(k+1)}=A_{y}^{(k)}+\left(m_{y}^{(k)}-m_{y}^{(k+1)}\right)\left(\frac{d \emptyset}{d z}-1\right)
\end{aligned}
$$

Using von Karman assumptions, Eqs. (19) to (24) can be written for strain components on a generic point of plate: 


$$
\begin{aligned}
& \varepsilon_{x}=\frac{\partial u}{\partial x}+\frac{1}{2}\left(\frac{\partial w}{\partial x}\right)^{2} \\
& \varepsilon_{y}=\frac{\partial v}{\partial y}+\frac{1}{2}\left(\frac{\partial w}{\partial y}\right)^{2} \\
& \varepsilon_{x y}=\frac{1}{2}\left(\frac{\partial v}{\partial x}+\frac{\partial u}{\partial y}\right) \\
& \varepsilon_{x y}=\frac{1}{2}\left(\frac{\partial v}{\partial x}+\frac{\partial u}{\partial y}\right) \\
& \varepsilon_{x z}=\frac{1}{2}\left(\frac{\partial w}{\partial x}+\frac{\partial u}{\partial z}\right) \\
& \varepsilon_{y z}=\frac{1}{2}\left(\frac{\partial w}{\partial y}+\frac{\partial v}{\partial z}\right)
\end{aligned}
$$

The generalized Hook law for linear elastic behavior of composite laminate can be expressed as

$$
\begin{gathered}
\sigma_{x x} \\
\left\{\begin{array}{c}
\sigma_{y y} \\
\sigma_{x y} \\
\sigma_{x z} \\
\sigma_{y z}
\end{array}\right\}
\end{gathered}=\left[\begin{array}{llll}
\bar{Q}_{11} & \bar{Q}_{12} & & \varepsilon_{x x} \\
\bar{Q}_{21} & \bar{Q}_{22} & \bar{Q}_{66} & \bar{Q}_{5 \underline{5}} \\
& & & \bar{Q}_{44}
\end{array}\right]\left[\begin{array}{c}
\varepsilon_{y y} \\
\varepsilon_{x y} \\
\varepsilon_{x z} \\
\varepsilon_{y z}
\end{array}\right\}
$$

where $\{\sigma\}$ and $\{\varepsilon\}$ are stress and strain components in the coordinate system of Fig.2, respectively. Also, $\bar{Q}_{\mathrm{ij}}(i, j=1,2,4,5,6)$ presents the transformed reduced material stiffness coefficients. The reduced material stiffness coefficients are given as

$$
\begin{aligned}
& Q_{11}=\frac{E_{11}}{1-v_{21} v_{12}}, Q_{22}=\frac{E_{22}}{1-v_{21} v_{12}}, Q_{12}=\frac{v_{21} E_{11}}{1-v_{21} v_{12}}, \\
& Q_{44}=G_{23}, Q_{55}=G_{13}, Q_{66}=G_{12}
\end{aligned}
$$

Using Hook law and shear stain formulas, the displacement field for the present ZZT can be expressed as

$$
\begin{aligned}
& u^{(k)}(\mathrm{x}, \mathrm{y}, \mathrm{z})=z \phi_{x}(x, y)+f_{x}^{(k)}(z)\left(\phi_{x}(x, y)+w_{, x}(x, y)\right) \\
& v^{(k)}(\mathrm{x}, \mathrm{y}, \mathrm{z})=z \phi_{y}(x, y)+f_{y}^{(k)}(z)\left(\phi_{y}(x, y)+w_{, y}(x, y)\right) \\
& w(\mathrm{x}, \mathrm{y}, \mathrm{z})=w(x, y)
\end{aligned}
$$


where $u, v, w, \phi_{x}, \phi_{y}$ are axial displacement of mid-plane in x-direction, axial displacement of mid-plane in y-direction, transverse displacement of mid-plane, rotation of cross section about xaxis and rotation of cross section about y-axis, respectively. The functions $f_{x}^{(k)}(z), f_{y}^{(k)}(z)$ are piece-wise continuous function to consider the variation of transverse stresses through the thickness can be expressed as

$$
f_{x}^{(k)}(z)=-z+g_{x}^{(k)}\left(z A_{x}^{(k)}+m_{x}^{(k)}(\varnothing-\mathrm{z})\right)+c_{x}^{(k)}
$$

and

$$
f_{y}^{(k)}(z)=-\mathrm{z}+g_{y}^{(k)}\left(z A_{y}^{(k)}+m_{y}^{(k)}(\varnothing-\mathrm{z})\right)+c_{y}^{(k)}
$$

In Eq. (30), displacement layer-wise constants in Xz-plane, $c_{x}^{(k)}$, are obtained by enforcing IC for displacement field. The neutral axis location and IC condition for displacement are given by

$$
\begin{aligned}
& u \stackrel{\left(k_{0}\right)}{x}=0 \\
& c_{x}^{\left(k_{9}\right)}=0
\end{aligned}
$$

and

$$
\begin{aligned}
u_{x}^{(k)} & =u_{x}^{(k+1)} \\
c_{x}^{(k)} & =\sum_{i=k_{0}^{+}+1}^{k}\left[\left(g_{x}^{(i-1)} A_{x}^{(i-1)}-g_{x}^{(i)} A_{x}^{(i)}\right) z_{i-1}-\left(g_{x}^{(i-1)} m_{x}^{(i-1)}-g_{x}^{(i)} m_{x}^{(i)}\right)(\varnothing-z)\right] \\
c_{x}^{(k)} & =\sum_{i=k}^{k_{0}-1}\left[\left(g_{x}^{(i+1)} A_{x}^{(i+1)}-g_{x}^{(i)} A_{x}^{(i)}\right) z_{i-1}-\left(g_{x}^{(i+1)} m_{x}^{(i+1)}-g_{x}^{(i)} m_{x}^{(i)}\right)(\emptyset-z)\right]
\end{aligned}
$$

In Eq. (31), displacement layer-wise constants in yz-plane, $c_{y}^{(k)}$, are determined as

$$
\begin{aligned}
& u_{y}^{\left(k_{0}\right)}=0 \\
& c_{y}^{\left(k_{n}\right)}=0
\end{aligned}
$$

and

$$
\begin{aligned}
& u_{y}^{(k)}=u_{y}^{(k+1)} \\
& c_{y}^{(k)}=\sum_{i=k_{0}^{-}+1}^{k}\left[\left(g_{y}^{(i-1)} A_{y}^{(i-1)}-g_{y}^{(i)} A_{y}^{(i)}\right) z_{i-1}-\left(g_{y}^{(i-1)} m_{y}^{(i-1)}-g_{y}^{(i)} m_{y}^{(i)}\right)(\varnothing-z)\right]
\end{aligned}
$$




$$
c_{y}^{(k)}=\sum_{i=k}^{k_{0}-1}\left[\left(g^{(i+1)} A_{y}^{(i+1)}-g_{y}^{(i)} A_{y}^{(i)}\right) z_{i-1}-\left(g_{y}^{(i+1)} m_{y}^{(i+1)}-g_{y}^{(i)} m_{y}^{(i)}\right)(\varnothing-z)\right]
$$

where neutral axis is located within layer $k_{0}$.

According to Eqs. (19) to (24), the strains can be expressed as

$$
\begin{aligned}
& \left\{\begin{array}{c}
\varepsilon_{x} \\
\varepsilon_{y} \\
\varepsilon_{x y}
\end{array}\right\}=\left\{\begin{array}{c}
\varepsilon_{x x}^{(n)}+z \varepsilon_{x x}^{(1)}+\left(f_{x}^{(k)}\right) \varepsilon_{x x}^{(f)} \\
\varepsilon_{x x}^{(n)}+z \varepsilon_{y y}^{(1)}+\left(f_{y}^{(k)}\right) \varepsilon_{y y}^{(f)} \\
z \varepsilon_{x y}^{(1)}+\left(f_{x}^{(k)}\right) \varepsilon_{x y}^{(f-x)}+\left(f_{y}^{(k)}\right) \varepsilon_{x y}^{(f-y)}
\end{array}\right\} \\
& \left\{\begin{array}{c}
\varepsilon_{x z} \\
\varepsilon_{y z}
\end{array}\right\}=\left\{\begin{array}{c}
\varepsilon_{x z}^{(n)} \\
\varepsilon_{y z}^{(n)}
\end{array}\right\}+\left\{\begin{array}{c}
\left(\frac{d f_{x}^{(k)}}{d z}\right) \varepsilon_{x z}^{(f)} \\
\left.d f_{y}^{(k)}\right) \\
\left(\frac{{ }^{(n)}}{d z}\right) \varepsilon_{y z}^{(f)}
\end{array}\right\}
\end{aligned}
$$

where

$$
\begin{aligned}
& \left\{\begin{array}{l}
\varepsilon_{x x}^{(n)} \\
\varepsilon_{y y}^{(n)}
\end{array}\right\}=\left\{\begin{array}{c}
\frac{1}{2}\left(\frac{\partial w}{\partial x}\right)^{2} \\
\frac{1}{2}\left(\frac{\partial w}{\partial y}\right)^{2}
\end{array}\right\},\left\{\begin{array}{c}
\varepsilon_{x x}^{(1)} \\
\varepsilon_{y y}^{(1)} \\
\varepsilon_{x y}^{(1)}
\end{array}\right\}=\left\{\begin{array}{c}
\phi_{x, x} \\
\phi_{y, y} \\
\phi_{x, y}+\phi_{y, x}
\end{array}\right\}, \\
& \left(\begin{array}{c}
\varepsilon_{x x}^{(f)} \\
\varepsilon_{y v}^{(f)} \\
\varepsilon^{(f-x)} \\
\varepsilon_{x v}^{(f-y)}
\end{array}\right\}=\left\{\begin{array}{l}
\phi_{x, x}+w_{, x x} \\
\phi_{y, y}+w_{, y y} \\
\phi_{x, y}+w_{, x y} \\
\phi_{y, x}+w_{, x y}
\end{array}\right\},\left\{\begin{array}{c}
\varepsilon_{x z}^{(n)} \\
\varepsilon_{y y}^{(n)}
\end{array}\right\}=\left\{\begin{array}{l}
\phi_{x}+\frac{\partial w}{\partial x} \\
\phi_{y}+\frac{\partial w}{\partial y}
\end{array}\right\},\left\{\begin{array}{l}
\varepsilon_{x z}^{(f)} \\
\varepsilon_{y y}^{(f)}
\end{array}\right\}=\left\{\begin{array}{l}
\phi_{x}+\frac{\partial w}{\partial x} \\
\phi_{y}+\frac{\partial w}{\partial y}
\end{array}\right\}
\end{aligned}
$$

\section{Equation of motions}

The partial differential equation of motion may be derived using the principle of minimum total potential energy:

$$
\delta \Pi=\delta U-\delta W
$$

Variation of strain energy and external work caused by virtual displacement can be expressed as

$$
\delta U=\iint_{A} \int_{-h / 2}^{h / 2} \delta \varepsilon^{T} \sigma d z d A
$$




$$
\delta W=\iint_{A}(q-k w) d A+\int_{-h / 2}^{h / 2} \hat{\sigma}_{n} \delta u_{n}+\hat{\sigma}_{n s} \delta u_{s}+\hat{\sigma}_{n z} \delta w-\iint_{A} \int_{h / 2}^{h / 2}(\ddot{u} \delta u+\ddot{v} \delta v+\ddot{w} \delta \imath)
$$

In Eq. (46), $A, \Gamma$ and $\mathrm{k}$ are reference plane area, plate boundary geometry and Winkler foundation parameter. The subscripts $\mathrm{n}$ and $\mathrm{s}$ represent directions normal and tangent to the boundary, respectively. Substituting Eqs. (45) and (46) into Eq. (44), assuming following definitions for force resultants $\left(N_{x x}, N_{y y}, N_{x y}\right)$ and moment resultants $\left(M_{x x}, M_{y y}, M_{x y}\right)$ :

$$
\left\{\begin{array}{l}
N_{x x} \\
N_{y y} \\
N_{x y}
\end{array}\right\}=\int_{-h / 2}^{h / 2}\left\{\begin{array}{l}
\sigma_{x x} \\
\sigma_{y y} \\
\sigma_{x y}
\end{array}\right\} d z,\left\{\begin{array}{l}
M_{x x} \\
M_{y y} \\
M_{x y}
\end{array}\right\}=\int_{-h / 2}^{h / 2}\left\{\begin{array}{l}
\sigma_{x x} \\
\sigma_{y y} \\
\sigma_{x y}
\end{array}\right\} z d z
$$

and defining high-order stress resultants $\left(P_{x x}, P_{y y}, P_{x y}\right),\left(R_{x}, R_{y}\right),\left(S_{x}, S_{y}\right)$ and $\left(T_{x}, T_{y}\right)$ as

$$
\left\{\begin{array}{l}
P_{x x} \\
P_{y y} \\
P_{x y}
\end{array}\right\}=\int_{-\frac{h}{2}}^{\frac{h}{2}}\left\{\begin{array}{l}
\sigma_{x x} \\
\sigma_{y y} \\
\sigma_{x y}
\end{array}\right\}\left(\mathrm{f}_{\mathrm{x}}^{(\mathrm{k})}(z)\right) d z,\left\{\begin{array}{l}
R_{x} \\
R_{y}
\end{array}\right\}=\int_{-\frac{h}{2}}^{\frac{h}{2}}\left\{\begin{array}{c}
\sigma_{x z} \\
\sigma_{y z}
\end{array}\right\} d z
$$

and

$$
\left\{\begin{array}{l}
Q_{x x} \\
Q_{y y} \\
Q_{x y}
\end{array}\right\}=\int_{-\frac{h}{2}}^{\frac{h}{2}}\left\{\begin{array}{l}
\sigma_{x x} \\
\sigma_{y y} \\
\sigma_{x y}
\end{array}\right\}\left(\mathrm{f}_{y}^{(\mathrm{k})}(z)\right) d z,\left\{\begin{array}{c}
S_{x} \\
S_{y}
\end{array}\right\}=\int_{-\frac{h}{2}}^{\frac{h}{2}}\left\{\begin{array}{l}
\sigma_{x z} \\
\sigma_{y z}
\end{array}\right\}\left(\frac{\mathrm{df}_{x}^{(\mathrm{k})}(z)}{d z}\right) d z,\left\{\begin{array}{l}
T_{x} \\
T_{y}
\end{array}\right\}=\int_{-\frac{h}{2}}^{\frac{h}{2}}\left\{\begin{array}{l}
\sigma_{x z} \\
\sigma_{y z}
\end{array}\right\}\left(\frac{\mathrm{df}_{y}^{(\mathrm{k})}(z)}{d z}\right) d z
$$

and utilizing green theorem

$$
\int_{A} f_{, i} d A=\int_{\Gamma} f n_{i} d A
$$

The governing equations of motions of the plate can be expressed as

$$
\begin{aligned}
& P_{x x, x x}+Q_{y y, y y}+Q_{x y, y x}+P_{x y, y x}-\left(R_{x}+S_{x}\right)_{, x}-\left(R_{y}+T_{y}\right)_{, y}+N(w)-k w+q=I_{0} \ddot{w} \\
& -M_{x x, x}-P_{x x, x}-M_{x y, y}-P_{x y, y}+R_{x}+S_{x}=I_{2} \ddot{\phi}_{x} \\
& -M_{y y, y}-Q_{y y, y}-M_{x y, x}-Q_{x y, x}+R_{y}+T_{y}=I_{2} \ddot{\phi}_{y}
\end{aligned}
$$

where

$$
N(w)=\left(N_{x x} w_{, x}+N_{x y} w_{, y}\right)_{, x}+\left(N_{x y} w_{, x}+N_{y y} w_{, y}\right)_{, y}
$$

In this study, it is assumed

$$
N_{x y}=0, N_{x x}=\bar{N}_{x x}, N_{y y}=\bar{N}_{y y}
$$

The stress resultants can be related to displacement field by the relations 


$$
\begin{aligned}
& M_{x x}=D_{11} \varepsilon_{x x}^{(1)}+F_{11}^{1} \varepsilon_{x x}^{(f)}+D_{12} \varepsilon_{y y}^{(1)}+F_{12}^{1} \varepsilon_{y y}^{(f)} \\
& M_{y y}=D_{22} \varepsilon_{y y}^{(1)}+F_{22}^{7} \varepsilon_{y y}^{(f)}+D_{12} \varepsilon_{x x}^{(1)}+F_{12}^{1} \varepsilon_{x x}^{(f)} \\
& M_{x y}=D_{66} \varepsilon_{x y}^{(1)}+F_{66}^{1} \varepsilon^{(f)}{ }_{x y}^{(f)}+F_{66}^{7} \varepsilon_{x y}^{(f-y)}
\end{aligned}
$$

and

$$
\begin{aligned}
& P_{x x}=F_{11}{ }_{1} \varepsilon_{x x}^{(1)}+H_{11} \varepsilon_{x x}^{(f)}+F_{12}^{1} \varepsilon_{y y}^{(1)}+H_{12}^{17} \varepsilon_{y y}^{(f)} \\
& P_{y y}=F_{12}^{1} \varepsilon_{x x}^{(1)}+H_{12}^{1} \varepsilon_{x x}^{(f)}+F_{22}^{1} \varepsilon_{y y}^{(1)}+H_{22}^{17} \varepsilon_{y y}^{(f)} \\
& P_{x y}=F_{66}^{1} \varepsilon_{x y}^{(1)}+H_{66}^{11} \varepsilon^{(f-x)}+H_{x y}^{17}{ }_{66} \varepsilon_{x y}^{(f-y)}
\end{aligned}
$$

and

$$
\begin{aligned}
& Q_{x x}=F_{11}^{2} \varepsilon_{x x}^{(1)}+H_{11}^{1} \varepsilon_{x x}^{(f)}+F_{12}^{?} \varepsilon_{y y}^{(1)}+H_{12}^{?} \varepsilon_{y y}^{(f)} \\
& Q_{y y}=F_{12}^{2} \varepsilon_{x x}^{(1)}+H_{12}^{1 ?} \varepsilon_{x x}^{(f)}+F_{22}^{?} \varepsilon_{y y}^{(1)}+H_{22}^{2} \varepsilon_{y y}^{(f)} \\
& Q_{x y}=F_{66}^{2} \varepsilon_{x y}^{(1)}+H_{66}^{17} \varepsilon_{x y}^{(f-x)}+H_{66}^{7} \varepsilon_{x y}^{(f-y)}
\end{aligned}
$$

and

$$
\begin{aligned}
& S_{x}=\left(A_{55}^{f}+F_{55}^{11}\right) \varepsilon_{x z} \\
& T_{y}=\left(A_{44}^{f}+F_{44}^{22}\right) \varepsilon_{y z}
\end{aligned}
$$

and

$$
\begin{aligned}
& R_{x}=\left(A_{55}^{f}+A_{55}\right) \varepsilon_{x z} \\
& R_{y}=\left(A_{44}^{f}+A_{44}\right) \varepsilon_{y z}
\end{aligned}
$$

The governing equation of the projectile is given as

$$
F_{c}=-m \ddot{\xi}=K_{e f f} \alpha^{\frac{3}{2}}
$$

where $\zeta, \alpha, \mathrm{m}_{\text {and }} \mathrm{K}_{\mathrm{eff}}$ represents displacement of the projectile, indentation of projectile, projectile mass and contact stiffness, respectively. The contact stiffness $\mathrm{K}_{\mathrm{eff}}$ is determined according to geometry and mechanical properties of the projectile and top layer of the plate.

$$
\begin{aligned}
& K_{\text {eff }}=\frac{4}{3} E \sqrt{R} \\
& \frac{1}{E}=\frac{1}{E_{\text {target }}}+\frac{1}{E_{\text {projectile }}}
\end{aligned}
$$




$$
\frac{1}{R}=\frac{1}{R_{\text {target }}}+\frac{1}{R_{\text {projectile }}}
$$

The indentation of projectile can be expressed as

$$
\alpha=\zeta-w(\xi, \eta)
$$

Eq. (59) can be rewritten as

$$
\ddot{w}=\left(\frac{-K_{\text {eff }}}{m}\right) \alpha^{\frac{3}{2}}-\ddot{\alpha}
$$

\section{Solution methodology}

Due to non-linear nature of impact events, there is no analytical solution. Therefore, Ritz method is employed to discretize the governing equations. The independent variables are expressed as series of spatial and temporal functions. For simply supported plate, the series are given as

$$
\begin{aligned}
& w(x, y, t)=\sum_{m=1} \sum_{n=1} W_{m n}(t) \sin \left(\frac{m \pi x}{a}\right) \sin \left(\frac{m \pi y}{b}\right) \\
& \phi_{x}(x, y, t)=\sum_{m=1} \sum_{n=1} X_{m n}(t) \cos \left(\frac{m \pi x}{a}\right) \sin \left(\frac{m \pi y}{b}\right) \\
& \phi_{y}(x, y, t)=\sum_{m=1} \sum_{n=1} Y_{m n}(t) \sin \left(\frac{m \pi x}{a}\right) \cos \left(\frac{m \pi y}{b}\right)
\end{aligned}
$$

where $\mathrm{m}$ and $\mathrm{n}$ are the numbers of terms in $\mathrm{x}$ and $\mathrm{y}$ directions in truncated series.

Furthermore, the impact load can be written as follows:

$$
\begin{aligned}
& q(x, y)=K_{e f f} \alpha^{\frac{3}{2}} \delta\left(x-x_{0}\right) \delta\left(y-y_{0}\right) \\
& q(x, y, t)=\sum_{m=1} \sum_{n=1} q_{m n}(t) \sin \left(\frac{m \pi x}{a}\right) \sin \left(\frac{m \pi y}{b}\right)
\end{aligned}
$$

where

$$
q_{m n}(t)=\frac{4 K_{e f f} \alpha^{\frac{3}{2}}}{a b} \sin \left(\frac{m \pi x_{0}}{a}\right) \sin \left(\frac{m \pi y_{0}}{b}\right)
$$

Substituting Eq. (65) into (64) give us the nonlinear governing equation of impact event: 


$$
\sum_{m=1} \sum_{n=1} \ddot{W}_{m n}(t) \sin \left(\frac{m \pi x_{0}}{a}\right) \sin \left(\frac{m \pi y_{0}}{b}\right)=\left(\frac{-K_{e f f}}{m}\right) \alpha^{\frac{3}{2}}-\ddot{\alpha}
$$

Substituting Eqs. (65) to (68) into Eqs. (51) to (58) obtains a $3 \times 3$ system of ordinary differential equations for the multilayer plate

$$
\left[\begin{array}{lll}
s_{11} & s_{12} & s_{13} \\
s_{12} & s_{22} & s_{23} \\
s_{13} & s_{23} & s_{33}
\end{array}\right]\left\{\begin{array}{l}
W_{m n} \\
X_{m n} \\
Y_{m n}
\end{array}\right\}+\left[\begin{array}{lll}
m_{11} & & \\
& m_{22} & \\
& & m_{33}
\end{array}\right]\left\{\begin{array}{l}
\ddot{W}_{m n} \\
\ddot{X}_{m n} \\
\ddot{Y}_{m n}
\end{array}\right\}=\left\{\begin{array}{c}
f_{m n} \\
0 \\
0
\end{array}\right\}
$$

where $s_{i j}$ and $m_{i j}$ are given by

$$
\begin{aligned}
& s_{11}=\left(A_{55}+2 A_{55}^{f r}+F_{55}^{11}\right) \alpha^{2}+\left(A_{44}+2 A_{44}^{f}+F_{44}^{\text {?) }}\right) \beta^{2}+H_{11}^{1} \alpha^{4} \\
& +\left(H_{66}^{11}+2 H_{12}^{17}+2 H_{66}^{17}+H_{66}^{7}\right) \alpha^{2} \beta^{2}+H_{22}^{2} \beta^{4}-k \\
& s_{12}=\left(A_{55}+2 A_{55}^{f x}+F_{55}^{11}\right) \alpha+\left(F_{11}^{1}+H_{11}^{1}\right) \alpha^{3}+\left(F_{12}^{?}+H_{12}^{17}+F_{66}^{2}+H_{66}^{11}+F_{66}^{1}+H_{66}^{17}\right) \alpha \\
& s_{13}=\left(A_{44}+2 A_{44}^{f_{1}}+F_{44}^{? 7}\right) \beta+\left(F_{22}^{?}+H_{22}^{2}\right) \beta^{3}+\left(F_{12}^{1}+H_{12}^{1 ?}+F_{66}^{1}+H_{66}^{17}+F_{66}^{?}+H_{66}^{?}\right) \alpha^{i} \\
& S_{22}=\left(A_{55}+2 A_{55}^{f}+F_{55}^{11}\right)+\left(H_{11}^{1}+2 F_{11}^{1}+D_{11}\right) \alpha^{2}+\left(H_{66}^{11}+2 F_{66}^{1}+D_{66}\right) \beta^{2} \\
& s_{23}=\left(D_{66}+H_{66}^{17}+F_{66}^{2}+F_{66}^{1}+D_{12}+2 F_{12}^{1}+H_{12}^{17}\right) \alpha \beta \\
& s_{33}=\left(A_{44}+2 A_{44}^{f_{1}}+F_{44}^{2}\right)+\left(H_{22}^{1 ?}+F_{22}^{2}+F_{22}^{1}+D_{22}\right) \beta^{2}+\left(H_{66}^{27}+2 F_{66}^{2}+D_{66}\right) \alpha^{2}
\end{aligned}
$$

and

$$
m_{11}=I_{0}, m_{22}=I_{2}, m_{33}=I_{22}
$$

and

$$
f_{m n}=\frac{4 K_{e f f}}{a b} \alpha^{\frac{3}{2}} \sin \left(\frac{m \pi x_{0}}{2 a}\right) \sin \left(\frac{m \pi y_{0}}{2 b}\right)+\bar{N}_{x x} \alpha^{2}+\bar{N}_{y y} \beta^{2}
$$

If $\mathrm{N}_{\mathrm{m}}$ and $\mathrm{N}_{\mathrm{n}}$ terms are chosen in $\mathrm{x}$ and y-direction, $\mathrm{N}_{\mathrm{m}} \times \mathrm{N}_{\mathrm{n}}+1$ equations describe the dynamic response of plate which must be solved simultaneously. This initial value problem of Eqs. (70) and (71) are solved using Runge-Kutta method implemented in Maple programming software. Fig. 4 illustrates the numerical procedure employed for the solution.

The governing equations reduce to those of FSDT [28] for $f_{y}^{(k)}=f_{x}^{(k)}=0, \mathrm{~A}^{(\mathrm{k})}=\mathrm{C}^{(\mathrm{k})}=0, \mathrm{~m}^{(\mathrm{k})}=\mathrm{g}^{(\mathrm{k})}=1$ as follows:

$$
s_{11}=\left(A_{55}\right) \alpha^{2}+\left(A_{44}\right) \beta^{2}
$$




$$
\begin{aligned}
& s_{12}=\left(A_{55}\right) \alpha \\
& s_{13}=\left(A_{44}\right) \beta \\
& s_{22}=\left(A_{55}\right)+\left(D_{11}\right) \alpha^{2}+\left(D_{66}\right) \beta^{2} \\
& s_{23}=\left(D_{66}+D_{12}\right) \alpha \beta \\
& s_{33}=\left(A_{44}\right)+\left(D_{22}\right) \beta^{2}+\left(D_{66}\right) \alpha^{2}
\end{aligned}
$$

Furthermore, the governing equations are reduced to those of HSDT [29] for $\varnothing=z\left(1-\frac{4}{3 h^{2}} z^{2}\right)$, $\mathrm{A}^{(\mathrm{k})}=\mathrm{C}^{(\mathrm{k})}=0, \mathrm{~m}^{(\mathrm{k})}=\mathrm{g}^{(\mathrm{k})}=1$ (i.e.: $\left.f_{y}^{(k)}=f_{x}^{(k)}=-\frac{4}{3 h^{2}} z^{3}=-c_{1} z^{3}\right)$.

$S_{11}$

$$
\begin{gathered}
=\left(A_{55}-6 c_{1} D_{55}+9 c_{1}^{7} F_{55}\right) \alpha^{2}+\left(A_{44}+-6 c_{1} D_{44}+9 c_{1}^{7} F_{44}\right) \beta^{2}+c_{1}^{3} \\
\left(H_{11} \alpha^{4}+\left(4 H_{66}+2 H_{12}+\right) \alpha^{2} \beta^{2}+H_{22} \beta^{4}\right) \\
s_{12}=\left(A_{55}-6 c_{1} D_{55}+9 c_{1}^{7} F_{55}\right) \alpha+c_{1}\left(-F_{11}+c_{1}^{7} H_{11}\right) \alpha^{3}+c_{1}\left(-F_{12}+c_{1} H_{12}-2 F_{66}\right. \\
\left.+2 c_{1} H_{66}\right) \alpha \beta^{2}
\end{gathered}
$$

$S_{13}$

$$
\begin{gathered}
\quad=\left(A_{44}-6 c_{1} D_{44}+9 c_{1}^{7} F_{44}\right) \beta+c_{1}\left(-F_{22}+c_{1} H_{22}\right) \beta^{3}+c_{1}\left(F_{12}+c_{1} H_{12}-21\right. \\
\alpha^{2} \beta \\
s_{22}=\left(A_{55}-6 C_{1} D_{55}+9 c_{1}^{7} F_{55}\right)+\left(c_{1}^{7} H_{11}-2 c_{1} F_{11}+D_{11}\right) \alpha^{2}+\left(c_{1}^{7} H_{66}-2 c_{1} F_{66}+D_{66}\right) \beta \\
s_{23}=\left(D_{66}-2 c_{1} F_{66}+c_{1}^{7} H_{66}+D_{12}-2 c_{1} F_{12}+c_{1}^{7} H_{12}\right) \alpha \beta \\
s_{33}=\left(A_{44}-6 c_{1} D_{44}+9 c_{1}^{7} F_{44}\right)+\left(c_{1}^{7} H_{22}^{1}-2 c_{1} F_{22}+D_{22}\right) \beta^{2}+\left(c_{1}^{7} H_{66}-2 c_{1} F_{66}+D_{66}\right) \alpha
\end{gathered}
$$

The components of stiffness and mass matrices are given in Appendix A.

\section{Results and discussions}

\subsection{Comparison studies}

In this section, two comparison studies are carried out with results of Khalili et al [30] and Pierson and vaziri [31]. Firstly, a simply supported plate with $200 \mathrm{~mm} \times 200 \mathrm{~mm}$ made of graphit/epoxy with layer arrangement $[0 / 90 / 0 / 90 / 0]_{\mathrm{s}}$ and following material properties [30]

$$
\begin{gathered}
E_{11}=141.2 \mathrm{GPa}, E_{22}=9.72 \mathrm{GPa}, v_{12}=0.3, \rho=1536 \frac{\mathrm{kg}}{\mathrm{m}^{3}} \\
G_{12}=5.53 \mathrm{GPa}, G_{13}=5.53 \mathrm{GPa}, G_{23}=3.74 \mathrm{GPa}
\end{gathered}
$$


with a rigid projectile with $12.7 \mathrm{~mm}$ diameter and $3 \mathrm{~m} / \mathrm{s}$ initial velocity is considered. Fig. 5 a) illustrates the time history of projectile contact force.

Secondly, a slightly different impact problem is considered from [31] (See Table 2 for specifications of plate and projectile). Fig. $5 \mathrm{~b}$ ) compares the time history of middle deflection of plate with that of [31]. The results are in good agreement with those of literature [30,31] and minor differences may be related to the different employed theories. Finally, in order to determine the sufficient terms for series approximation in Ritz solution, a sensitivity analysis is carried out (Fig. 6 a)). Furthermore, the variation of maximum contact force versus the number of terms is shown in Fig. 6 b). It is clear that 15 terms are sufficient to reach reasonable accuracy.

\subsection{Parametric studies}

In this part, in order to investigate the effect of various parameters such as plate thickness, projectile velocity, projectile radius, in-plane load and impact location, some numerical examples were given. The rectangular Fiber Metal Laminate plate [Al/0/90/90/0/Al/0/90/90/0/Al] was considered which impacted by the previous spherical projectile (See Table 2 for mechanical properties of composite layers and Table 3 for other specifications).

\subsubsection{Effect of laminate thickness}

Fig. 7 indicates comparison of time history of contact forces obtained using Present ZZT, HSDT and FSDT for simply supported FML having total thickness $h$ and $h / 2$, respectively (See Table 3 ). The major difference between results obtained using various theories shows that considering shear deformation and IC plays an important role in reaching accurate time duration and maximum contact force. In fact, omitting IC condition causes overestimating of time duration and maximum contact force.

\subsubsection{Effect of projectile velocity}

In order to study influence of projectile velocity, the FML plate was impacted with three initial velocity $1,2,4 \mathrm{~m} / \mathrm{s}$ as shown in Fig. 8. The projectile mass was chosen as $\mathrm{M}=32.7,8.2,2 \mathrm{~g}$ to 
achieve fixed kinetic energy. The results demonstrate that the increase of initial velocity causes permanently increase of maximum of contact force (MCF) and maximum deflection of middle of target (MDMT); however; contact time (CT) decrease. As a result, the MCF and MDMT are proportional to projectile velocity and projectile mass. The obtained results are compatible with those of [32].

\subsubsection{Projectile radius}

The effect of projectile radius is study herein and the results are depicted in Fig. 9. Three radii $\mathrm{R}=10,20,30 \mathrm{~mm}$ and projectile mass $\mathrm{M}=32.7 \mathrm{~g}$ were considered. Since the projectile mass is only variable, its effects on impact behavior can be observed in Fig.9. The results indicate that increase of projectile radius causes increase of MDMT and MCF and decrease of MCF. Because contact stiffness increases when projectile radius increase regarding Eq. (60). These obtained results are in good agreement with those of [27].

\subsubsection{Effect of the In-plane load}

To investigate the influence of the in-plane load on indentation, CF, MDMT, three in-plane biaxial loading cases are chosen:

$$
\text { Case 1:N=+0.04 N/mm, Case 2: } \mathrm{N}=0, \quad \text { Case3: } \mathrm{N}=-0.04 \mathrm{~N} / \mathrm{mm}
$$

The obtained results are demonstrated in Fig. 10. Because of varying only on parameter, it can be used to predict dynamic response of FML plate for various in-plane load. As shown in the figure, compressive in-plane load causes decrease of MCF and CT in contrast to tensile in-plane load. Furturemore, compressive in-plane load increases MDMT. Because the effective flexural rigidity of plate decreases when compressive load applied. These results are compatible with reported one in [33].

\subsubsection{Eccentric impact}

To assess effect of an eccentric impact on the FMLs, it is assumed that projectile collides with the plate at below points: 


$$
\mathrm{x}_{0} / \mathrm{a}, \mathrm{y}_{0} / \mathrm{b}=\{(1 / 4,1 / 4),(1 / 3,1 / 3),(2 / 5,2 / 5),(1 / 2,1 / 2)\}
$$

Fig. 11 depicts contact force history and middle deflection of plate for four cases of projectile position. As can be seen in Fig. 11, MCF increases when impact point approaches the edge of the plate due to higher flexural stiffness in neighborhoods of edges of the plate. Accordingly, when impact point approaches the edges of plate, the value of MDMT decreases. This matches the one reported in [28].

\section{Conclusions}

In this paper, the eccentric low-velocity impact of FMLs subject to spherical projectile using a unified ZigZag plate theory was investigated. The presented zig-zag plate theory enforces shear stress continuity through the thickness via piece-wise continues stress field. The model was validated by comparison and good agreement between its results and those of reports in open literature. Influence of various specifications of impact phenomenon such as laminate thickness, projectile radius, projectile velocity, inplane load and eccentricity parameter was examined on deflection and contact force time history. The following conclusions can be drawn from this study:

- The results indicate that continuity of transverse shear stress is required to achieve accurate stress distribution through the thickness even for moderately FML.

- $\mathrm{MCF}$ and MDMT are proportional to projectile velocity and projectile mass.

- Increase of projectile radius causes increase of MDMT and MCF and decrease of MCF

- Compressive in-plane load causes decrease of MCF and CT in contrast to tensile in-plane load.

- $\mathrm{MCF}$ increases when impact point approaches the edge of plate due to higher flexural stiffness neighborhoods of edges of plate, however, MDMT decreases.

\section{Acknowledgment}

The authors are thankful to the Tarbiat Modares University (TMU) for their financial support. 


\section{Appendix A}

$$
\begin{aligned}
& A_{i j}=\sum_{k=1}^{N_{L}} \int_{Z[k]}^{Z[k+1]} \bar{Q}_{i j}^{(k)} d z ; \quad i, j=4,5 \\
& D_{i j}=\sum_{k=1}^{N_{L}} \int_{Z[k]}^{Z[k+1]} \bar{Q}_{i j}^{(k)} z^{2} d z ; \quad i, j=1,2,6 \\
& A_{i j}^{f x}=\sum_{k=1}^{N_{L}} \int_{Z[k]}^{Z[k+1]} \bar{Q}_{i j}^{(k)} \frac{d f^{(k)} x}{d z} d z ; \quad i, j=4,5 \\
& A_{i j}^{f y}=\sum_{k=1}^{N_{L}} \int_{Z[k]}^{Z[k+1]} \bar{Q}_{i j}^{(k)} \frac{d f^{(k)} y}{d z} d z ; \quad i, j=4,5 \\
& F_{i j}^{11}=\sum_{k=1}^{N_{L}} \int_{Z[k]}^{Z[k+1]} \bar{Q}_{i j}^{(k)} \frac{d f_{x}^{2}}{d z} d z ; \quad i, j=4,5 \\
& F_{i j}^{22}=\sum_{k=1}^{N_{L}} \int_{Z[k]}^{Z[k+1]} \bar{Q}_{i j}^{(k)} \frac{d f_{y}{ }^{2}}{d z} d z ; \quad i, j=4,5 \\
& F_{i j}^{11}=\sum_{k=1}^{N_{L}} \int_{Z[k]}^{Z[k+1]} \bar{Q}_{i j}^{(k)} z f_{x}^{(k)} d z ; \quad i, j=1,2,6 \\
& F_{i j}^{22}=\sum_{k=1}^{N_{L}} \int_{Z[k]}^{Z[k+1]} \bar{Q}_{i j Z}^{(k)} z f_{y}^{(k)} d z ; \quad i, j=1,2,6 \\
& H_{i j}^{11}=\sum_{k=1}^{N_{L}} \int_{Z[k]}^{Z[k+1]} \bar{Q}_{i j}^{(k)}\left(f^{(k)}\right)^{2} d z ; \quad i, j=1,2,6 \\
& H_{i j}^{22}=\sum_{k=1}^{N_{L}} \int_{Z[k]}^{Z[k+1]} \bar{Q}_{i j}^{(k)}\left(f^{(k)} y\right)^{2} d z ; \quad i, j=1,2,6
\end{aligned}
$$


$H_{i j}^{12}=\sum_{k=1}^{N_{L}} \int_{Z[k]}^{Z[k+1]} \bar{Q}_{i j}^{(k)} f_{x}^{(k)} f_{y}^{(k)} d z ; \quad i, j=1,2,6$

$I_{0}=\sum_{k=1}^{N_{L}} \int_{Z[k]}^{Z[k+1]} \rho^{(k)} d z$

$I_{2}=\sum_{k=1}^{N_{L}} \int_{Z[k]}^{Z[k+1]} \rho^{(k)} Z^{2} d Z$

where $\mathrm{N}_{\mathrm{L}}$ represents the number of FML layers.

\section{References}

[1] Sadighi M, Alderliesten RC, Benedictus R. Impact resistance of fiber-metal laminates: A review. International Journal of Impact Engineering 2012;49:77-90. doi:10.1016/j.ijimpeng.2012.05.006.

[2] Seo H, Hundley J, Hahn HT, Yang J-M. Numerical Simulation of Glass-Fiber-Reinforced Aluminum Laminates with Diverse Impact Damage. AIAA Journal 2010;48:676-87. doi:10.2514/1.45551.

[3] Ghalami-Choobar M, Sadighi M. Investigation of high velocity impact of cylindrical projectile on sandwich panels with fiber-metal laminates skins and polyurethane core. Aerospace Science and Technology 2014;32:142-52.

[4] Zarei H, Brugo T, Belcari J, Bisadi H, Minak G, Zucchelli A. Low velocity impact damage assessment of GLARE fiber-metal laminates interleaved by Nylon 6,6 nanofiber mats. Composite Structures 2017;167:123-31. doi:10.1016/j.compstruct.2017.01.079.

[5] Chai GB, Manikandan P. Low velocity impact response of fibre-metal laminates - A review. Composite Structures 2014;107:363-81. doi:10.1016/j.compstruct.2013.08.003.

[6] Ahmadi H, Liaghat G, Sabouri H, Bidkhouri E. Investigation on the high velocity impact properties of glass-reinforced fiber metal laminates. Journal of Composite Materials 2013;47:1605-15.

[7] Groh RMJ, Weaver PM. On displacement-based and mixed-variational equivalent single layer theories for modelling highly heterogeneous laminated beams. International Journal of Solids and Structures 2015;59:147-70.

[8] Carrera E. Historical review of Zig-Zag theories for multilayered plates and shells. Appl Mech Rev 2003;56:287-308. doi:10.1115/1.1557614.

[9] Afshin M, Sadighi M, Shakeri M. Static Analysis of Cylindrical Sandwich Panels with a Flexible Core and Laminated Composite Face Sheets. Journal of Composite Materials 2010;44:1455-76.

[10] Gherlone M. On the Use of Zigzag Functions in Equivalent Single Layer Theories for Laminated Composite and Sandwich Beams: A Comparative Study and Some Observations on External Weak Layers. J Appl Mech 2013;80:061004. 
[11] Carrera E. Theories and Finite Elements for Multilayered Plates and Shells: A Unified compact formulation with numerical assessment and benchmarking. ARCO 2003;10:21596. doi:10.1007/BF02736224.

[12] Carrera E. On the use of the Murakami's zig-zag function in the modeling of layered plates and shells. Computers \& Structures 2004;82:541-54. doi:10.1016/j.compstruc.2004.02.006.

[13] Brischetto S, Carrera E, Demasi L. Improved bending analysis of sandwich plates using a zig-zag function. Composite Structures 2009;89:408-15.

[14] Groh RMJ, Weaver PM. A computationally efficient 2D model for inherently equilibrated 3D stress predictions in heterogeneous laminated plates. Part II: Model validation. Composite Structures 2016;156:186-217. doi:10.1016/j.compstruct.2015.11.077.

[15] Groh RMJ, Weaver PM. A computationally efficient 2D model for inherently equilibrated 3D stress predictions in heterogeneous laminated plates. Part I: Model formulation. Composite Structures 2016;156:171-85. doi:10.1016/j.compstruct.2015.11.078.

[16] Abrate S. Impact on Composite Structures. Cambridge: Cambridge University Press; 1998. doi:10.1017/CBO9780511574504.

[17] Malekzadeh K, Khalili MR, Mittal RK. Analytical Prediction of Low-velocity Impact Response of Composite Sandwich Panels using New TDOF Spring-mass-damper Model. Journal of Composite Materials 2006;40:1671-89. doi:10.1177/0021998306060170.

[18] Singh H, Mahajan P. Analytical modeling of low velocity large mass impact on composite plate including damage evolution. Composite Structures 2016;149:79-92. doi:10.1016/j.compstruct.2016.04.009.

[19] Mamivand M, Liaghat GH. A model for ballistic impact on multi-layer fabric targets. International Journal of Impact Engineering 2010;37:806-12.

[20] Shivakumar KN, Elber W, Illg W. Prediction of Impact Force and Duration Due to LowVelocity Impact on Circular Composite Laminates. Journal of Applied Mechanics 1985;52:674-80. doi:10.1115/1.3169120.

[21] Hoo Fatt MS, Lin C, Revilock DM, Hopkins DA. Ballistic impact of GLARE ${ }^{\mathrm{TM}}$ fibermetal laminates. Composite Structures 2003;61:73-88. doi:10.1016/S0263-8223(03)000369.

[22] Sadeghpour E, Afshin M, Sadighi M. A theoretical investigation on low-velocity impact response of a curved sandwich beam. International Journal of Mechanical Sciences 2015;101-102:21-8. doi:10.1016/j.ijmecsci.2015.07.011.

[23] Vlot A. Impact loading on fibre metal laminates. International Journal of Impact Engineering 1996;18:291-307. doi:10.1016/0734-743X(96)89050-6.

[24] Tsamasphyros GJ, Bikakis GS. Dynamic response of circular GLARE fiber-metal laminates subjected to low velocity impact. Journal of Reinforced Plastics and Composites 2011;30:978-87. doi:10.1177/0731684411411226.

[25] Bikakis GSE. Simulation of the dynamic response of GLARE plates subjected to low velocity impact using a linearized spring-mass model. Aerospace Science and Technology 2017;64:24-30. doi:10.1016/j.ast.2017.01.013.

[26] Morinière FD, Alderliesten RC, Sadighi M, Benedictus R. An integrated study on the lowvelocity impact response of the GLARE fibre-metal laminate. Composite Structures 2013;100:89-103. doi:10.1016/j.compstruct.2012.12.016.

[27] Zarei H, Fallah M, Minak G, Bisadi H, Daneshmehr A. Low velocity impact analysis of Fiber Metal Laminates (FMLs) in thermal environments with various boundary conditions. Composite Structures 2016;149:170-83. doi:10.1016/j.compstruct.2016.04.036. 
[28] Shariyat M, Farzan F. Nonlinear eccentric low-velocity impact analysis of a highly prestressed FGM rectangular plate, using a refined contact law. Archive of Applied Mechanics 2013;83:623-41. doi:10.1007/s00419-012-0708-3.

[29] Reddy JN. A Simple Higher-Order Theory for Laminated Composite Plates. Journal of Applied Mechanics 1984;51:745-52.

[30] Khalili SMR, Soroush M, Davar A, Rahmani O. Finite element modeling of low-velocity impact on laminated composite plates and cylindrical shells. Composite Structures 2011;93:1363-75. doi:10.1016/j.compstruct.2010.10.003.

[31] Pierson MO, Vaziri R. Analytical solution for low-velocity impact response of composite plates. AIAA Journal 1996;34:1633-40. doi:10.2514/3.13282.

[32] Kiani Y, Sadighi M, Salami SJ, Eslami MR. Low velocity impact response of thick FGM beams with general boundary conditions in thermal field. Composite Structures 2013;104:293-303. doi:10.1016/j.compstruct.2013.05.002.

[33] Malekzadeh K, Khalili MR, Mittal RK. Response of In-plane Linearly Prestressed Composite Sandwich Panels with Transversely Flexible Core to Low-velocity Impact. Jnl of Sandwich Structures \& Materials 2006;8:157-81. doi:10.1177/1099636206060137. 


\section{Figure captions}

Fig. 1 Arrangement of GALRE laminate a) GALRE 5-2/1 b) GLARE 4-3/2 [2]

Fig. 2 The piece-wise continuous displacement field and change of slope through the thickness (ZZ phenomenon) due to transverse shear stress continuity

Fig. 3 A rectangular FML plate subjected to transverse impact and its geometry

Fig.4 Flowchart of numerical procedure

Fig. 5 Comparison of time history of contact force (a) and middle deflection (b) of the composite laminated plate subjected to central impact by spherical projectile with those of [30] and [31], respectively.

Fig. 6 Convergence study of a) time history of contact force b) peak contact force on number of terms in series

Fig. 7 Comparison of time history of contact force obtained via present Unified ZZT and other theories for FML plate subjected to central impact for thickness $t$ (a) and $t / 2$ (b)

Fig. 8 Influence of projectile velocity on impact response of FML plate.

Fig. 9 Influence of projectile radius on impact response of FML plate.

Fig. 10 Influence of in-plane load on impact response of FML plate.

Fig. 11 Influence of impact location on impact response of FML plate. 


\section{Tables}

Table 1: Some shape functions utilized to achieve various plate theories via present Unified ZZT

\begin{tabular}{cc}
\hline Shape function name & $\varnothing(\mathrm{z})$ \\
\hline EBDT & 0 \\
FSDT & $z\left(1-\frac{4 z^{2}}{3}\right)$ \\
Reddy's HSDT & $\frac{h}{\pi} \sin \left(\frac{\pi z}{h}\right)$ \\
Touratier's HSDT & $z e^{-2\left(\frac{z}{h}\right)^{2}}$ \\
Karama's HSDT & \\
\hline
\end{tabular}


Table 2: Geometrical and mechanical specification of the impact problem from [31]

\begin{tabular}{|c|c|c|}
\hline & Geometrical Properties & Mechanical properties \\
\hline \multirow[t]{2}{*}{ Projectile } & Initial velocity $=3 \mathrm{~m} / \mathrm{s}$ & $E_{11}=210 \mathrm{GPa}$ \\
\hline & Radius $=12.7 \mathrm{~mm}, M=8.5 \mathrm{~g}$ & $v=0.3$ \\
\hline \multirow[t]{7}{*}{ Plate } & $200 \times 200 \times 2.69 \mathrm{~mm}$ & $E_{11}=141.2 \mathrm{GPa}$ \\
\hline & {$[0 / 90 / 0 / 90 / 0]_{\mathrm{s}}$} & $E_{22}=9.72 \mathrm{GPa}$ \\
\hline & & $v_{12}=0.3$ \\
\hline & & $\rho=1536 \frac{\mathrm{kg}}{\mathrm{m}^{3}}$ \\
\hline & & $G_{12}=5.53 \mathrm{GPa}$ \\
\hline & & $G_{13}=5.53 \mathrm{GPa}$ \\
\hline & & $G_{23}=3.74 G P a$ \\
\hline
\end{tabular}

Table 3: Geometrical and mechanical specification of FML plate

$$
\begin{gathered}
E=70 G P a, v=0.3 \\
\mathrm{a}=200 \mathrm{~mm}, \mathrm{~b}=200 \mathrm{~mm}
\end{gathered}
$$

Aluminum thickness $\mathrm{h}_{\mathrm{al}}=0.5 \mathrm{~mm}$

Total thickness $\mathrm{h}=4.3 \mathrm{~mm}$ 


\section{Figures}

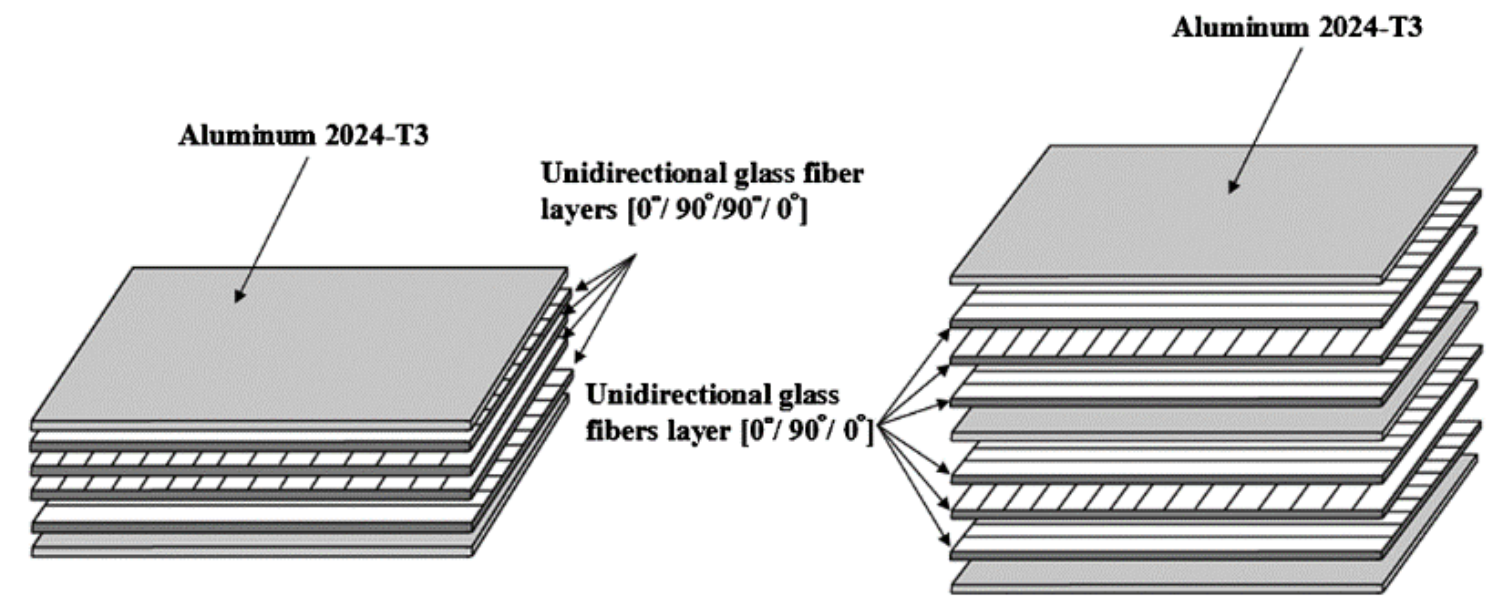

a)

b)

Fig. 1

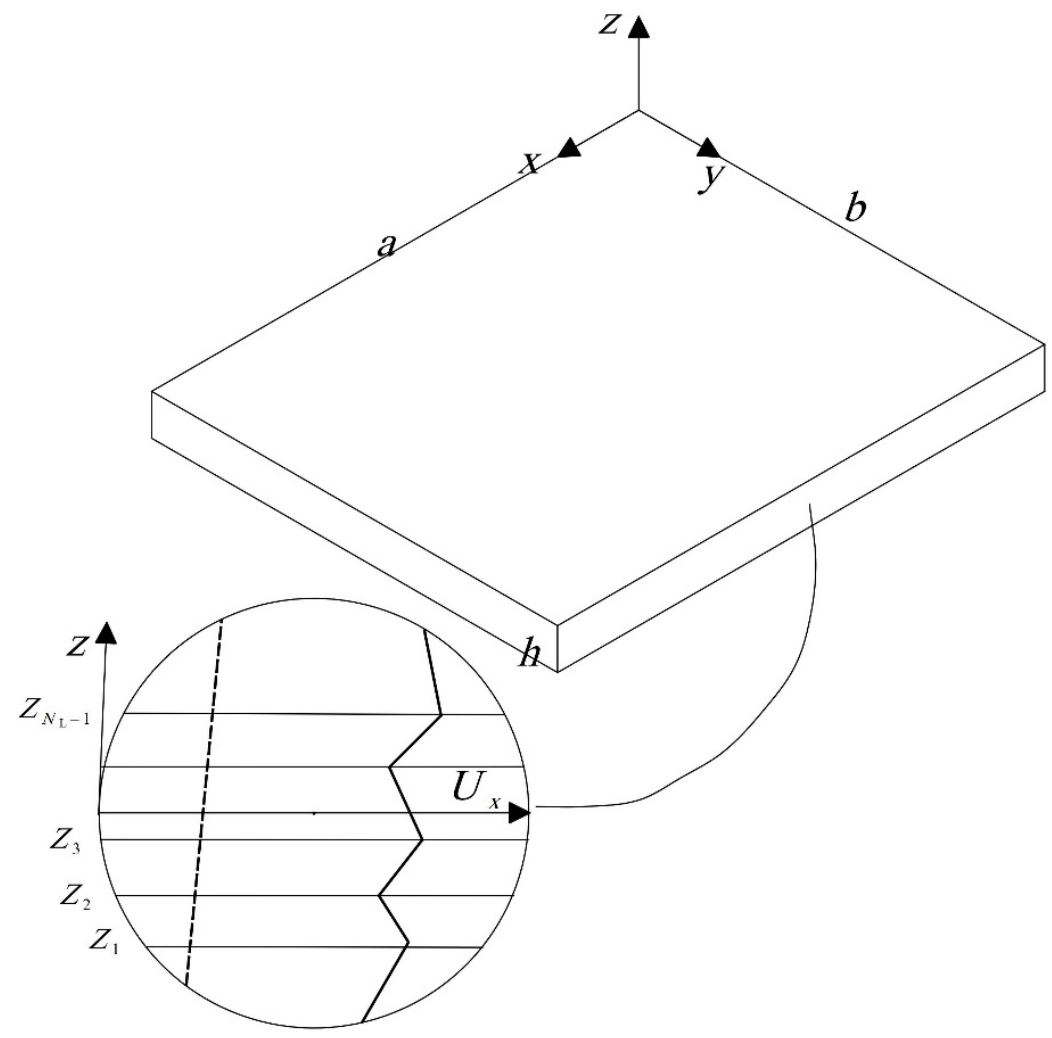

In-plane displacement field (FSDT(dashed---), Exact(solid-) )

Fig. 2 


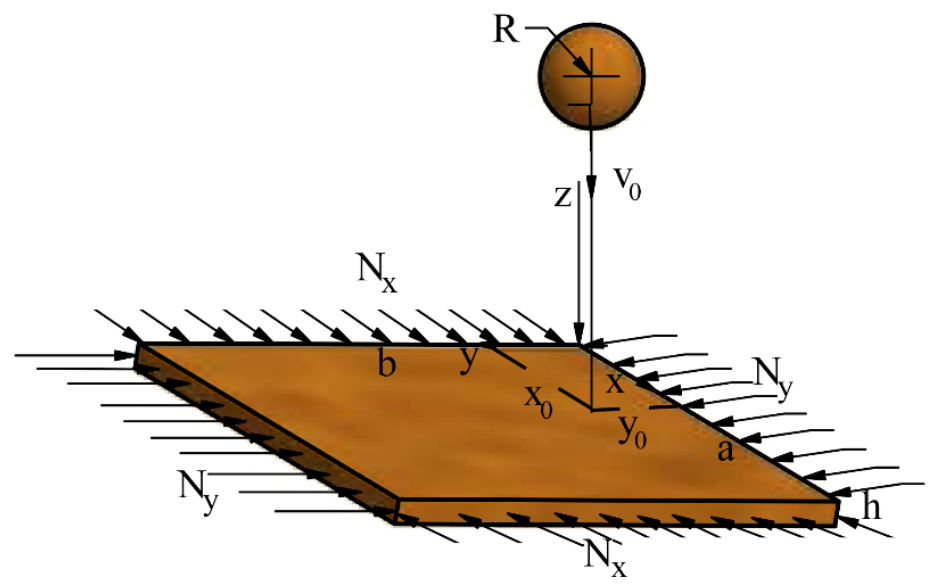

Fig.3 


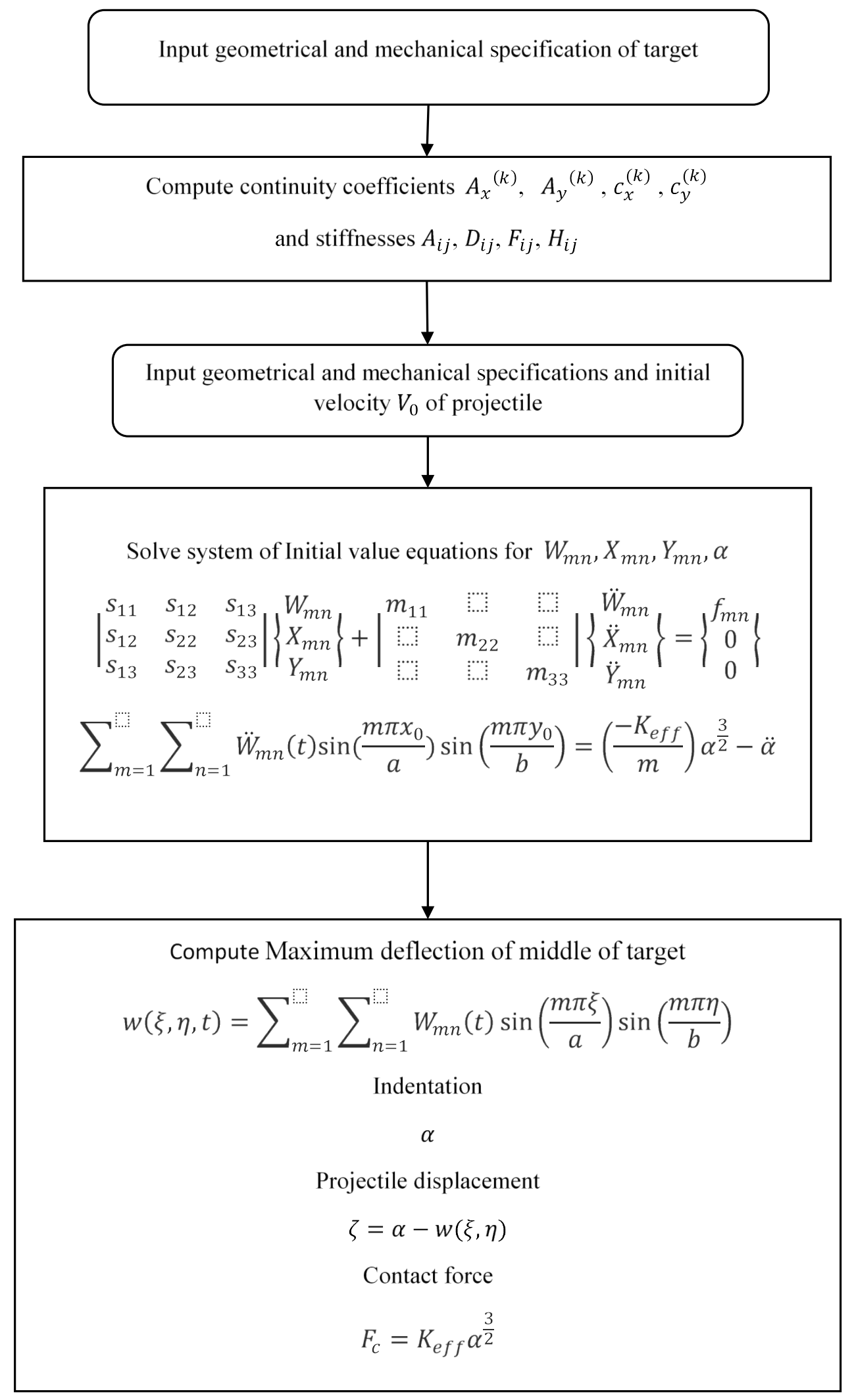

Fig.4 Flowchart of numerical procedure 


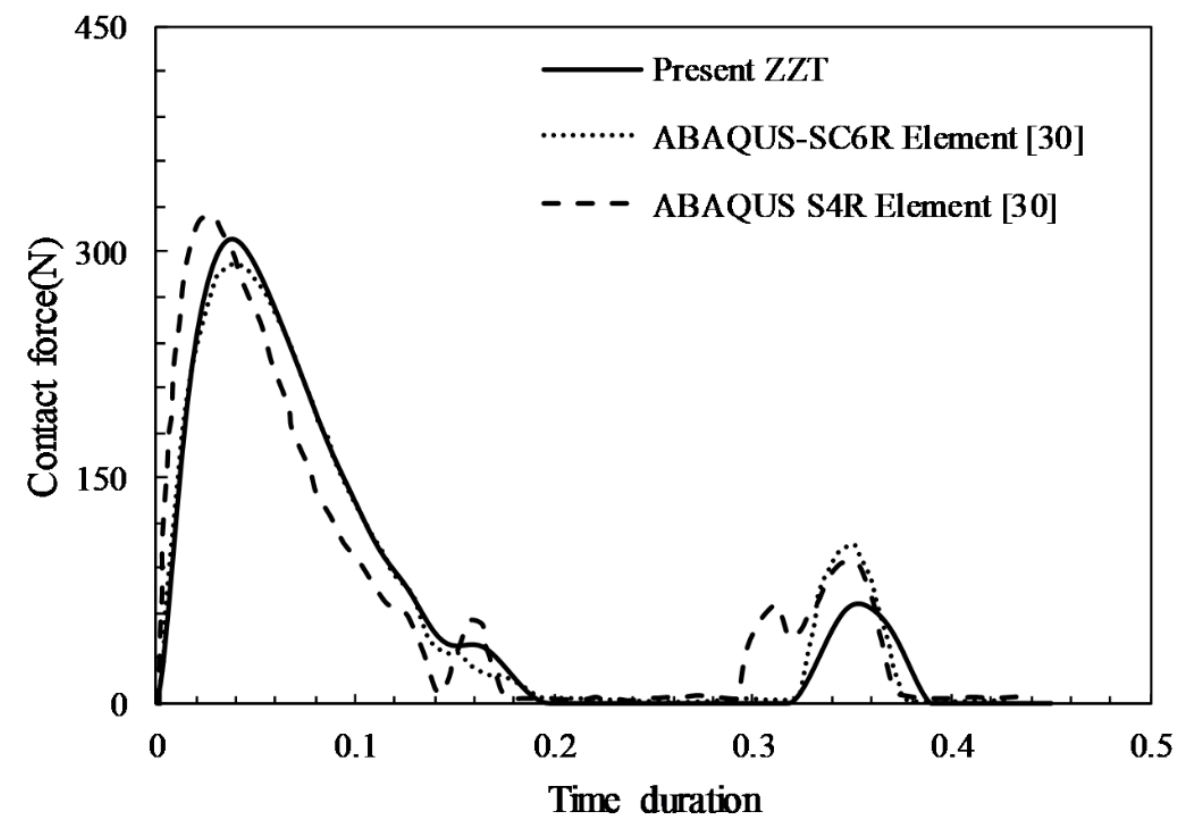

a)

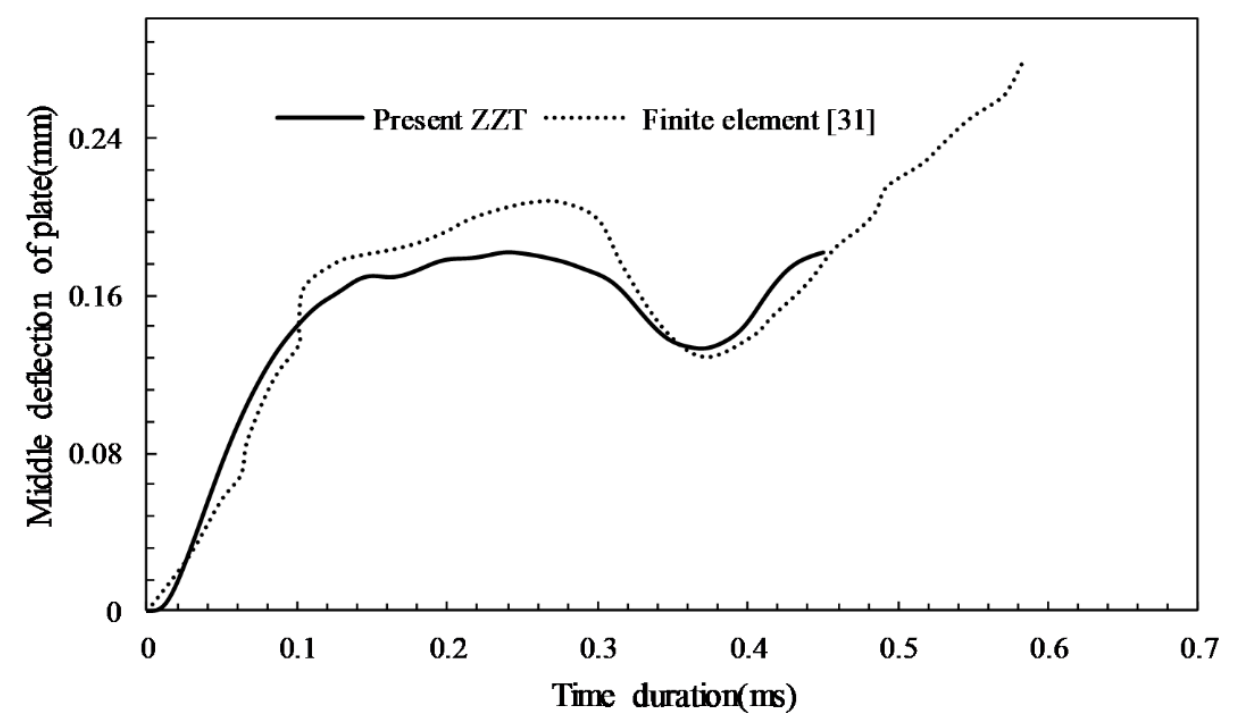

b)

Fig.5 


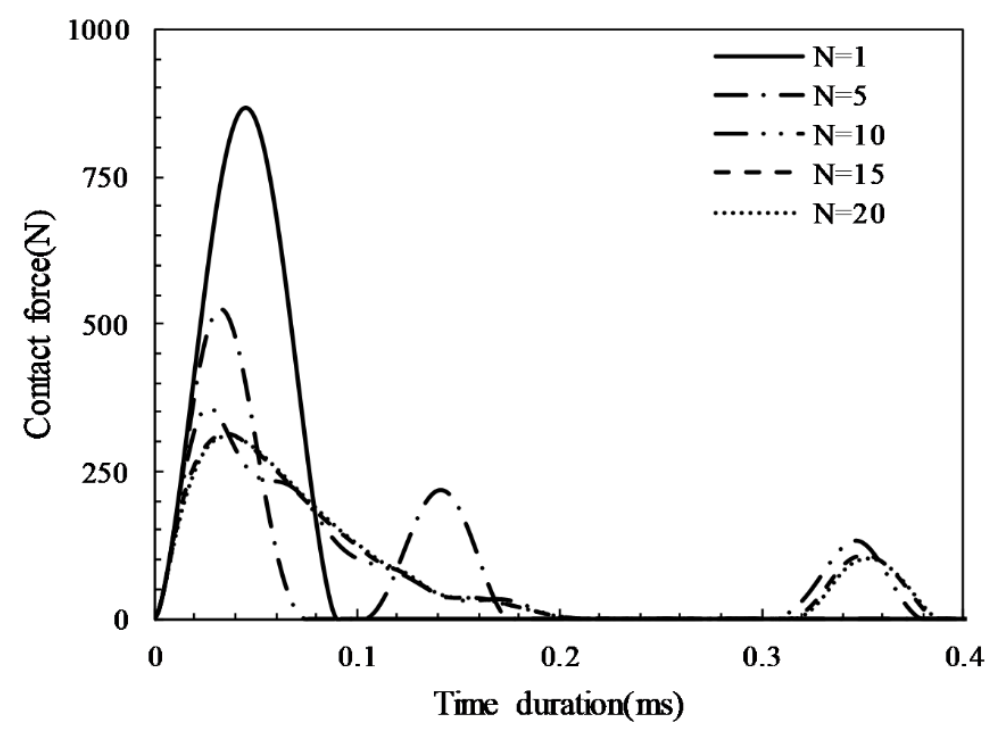

a)

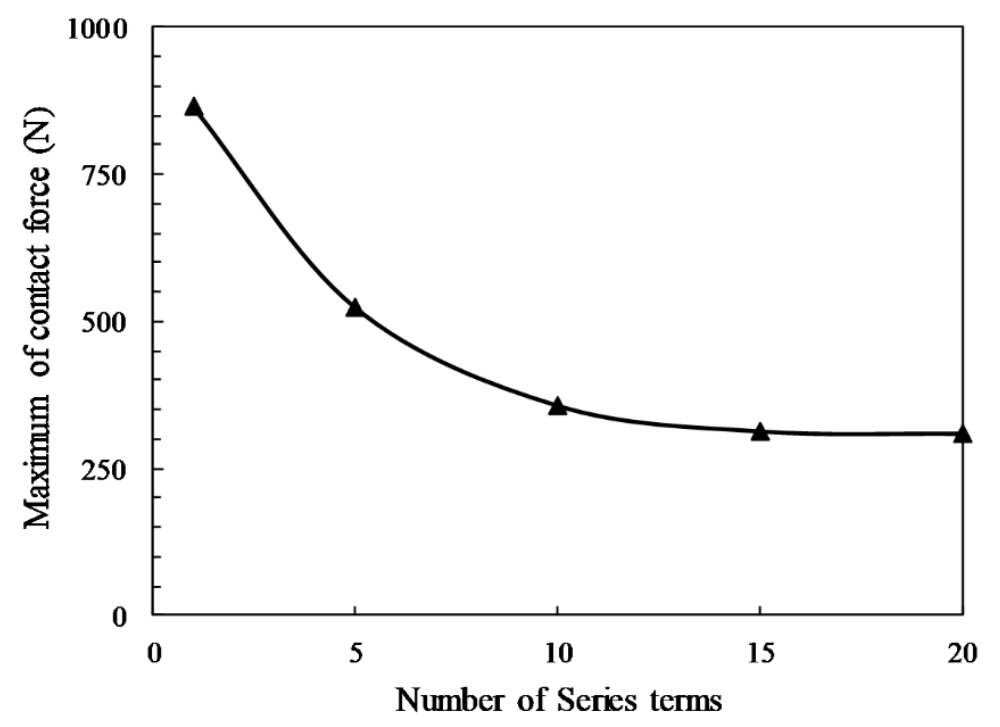

b)

Fig.6 


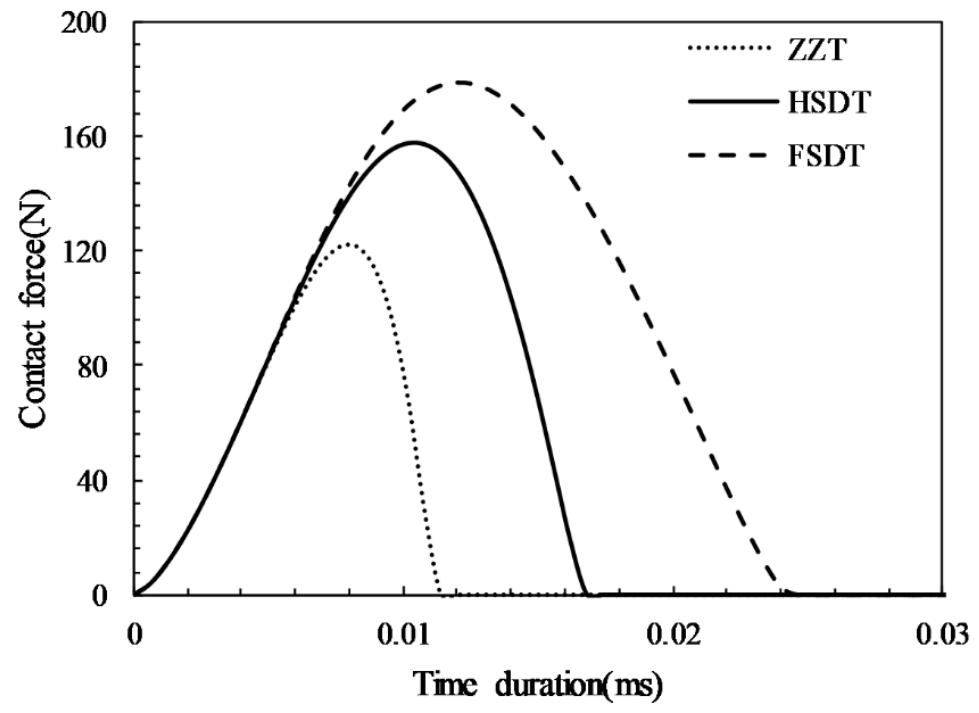

a)

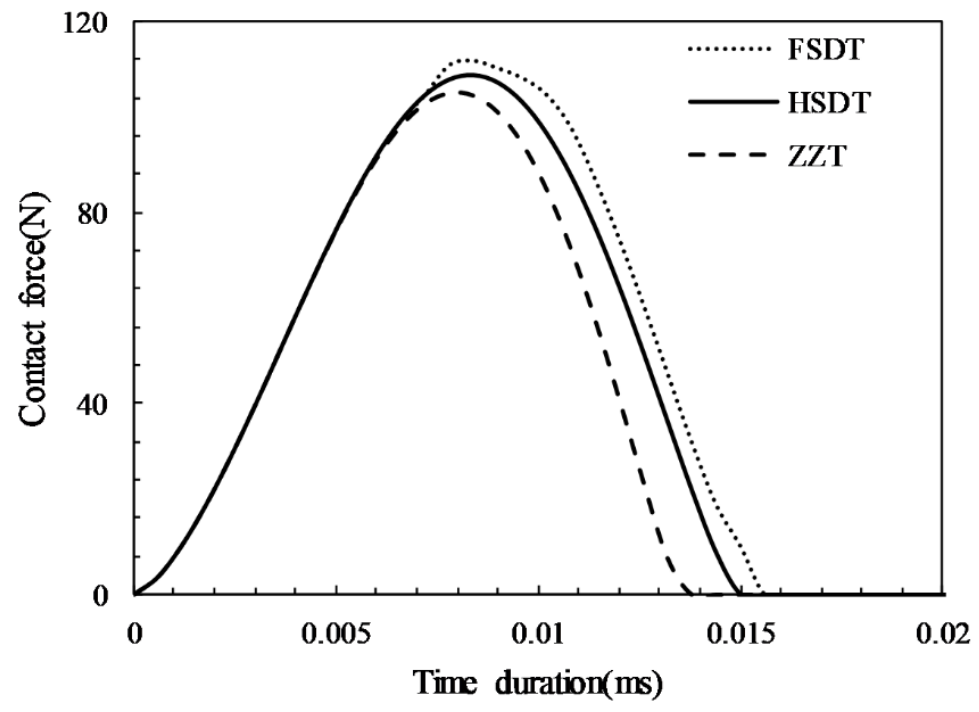

b)

Fig. 7 


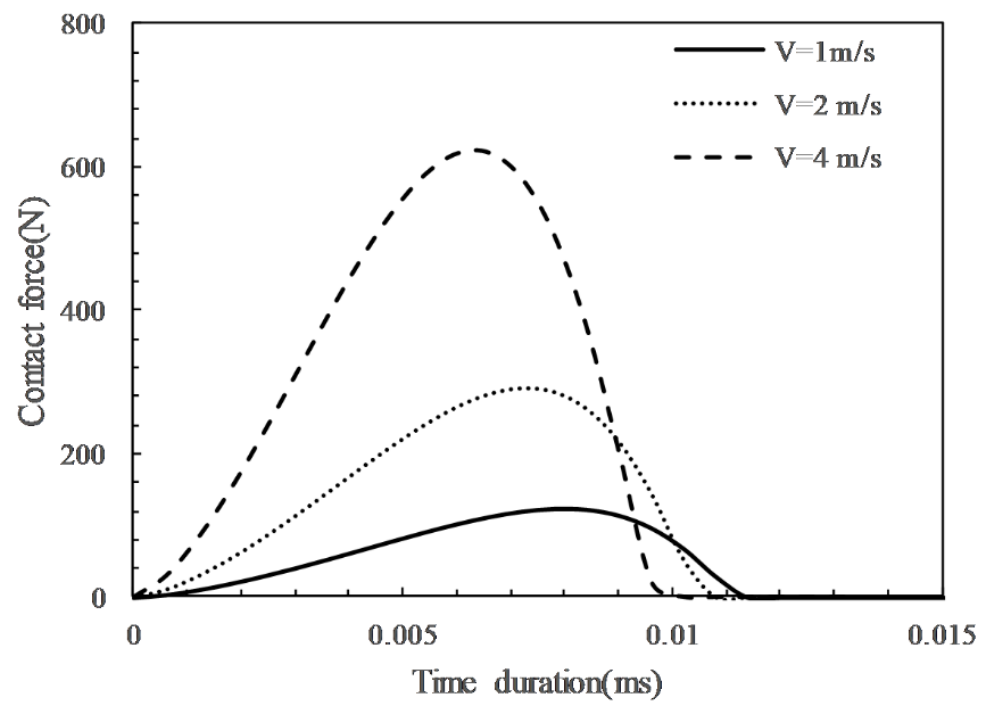

a)

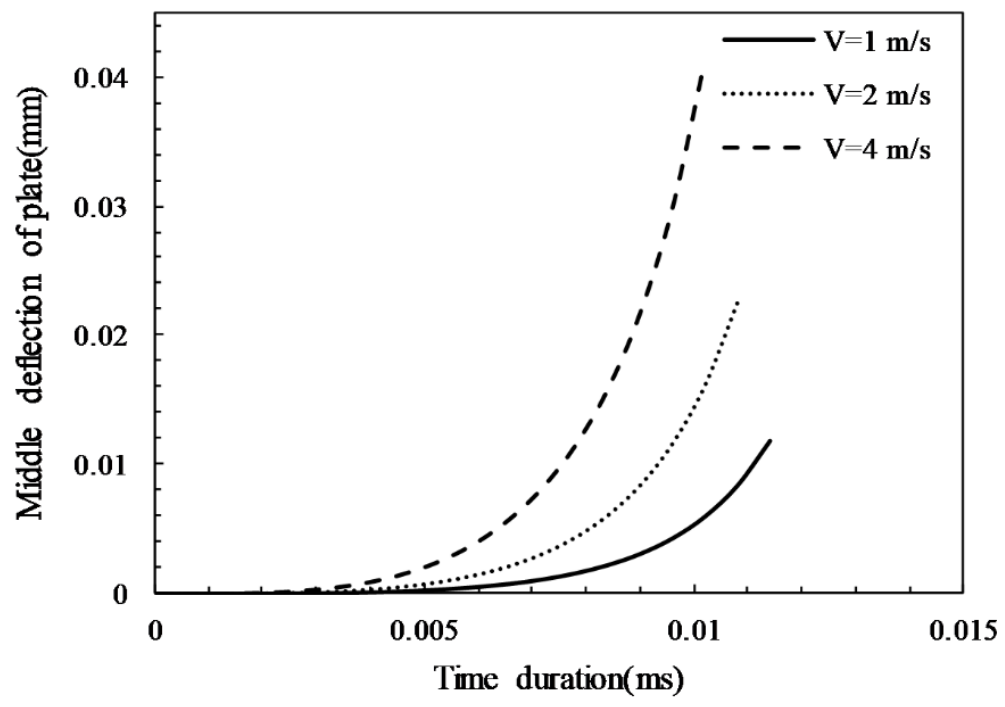

b)

Fig. 8 


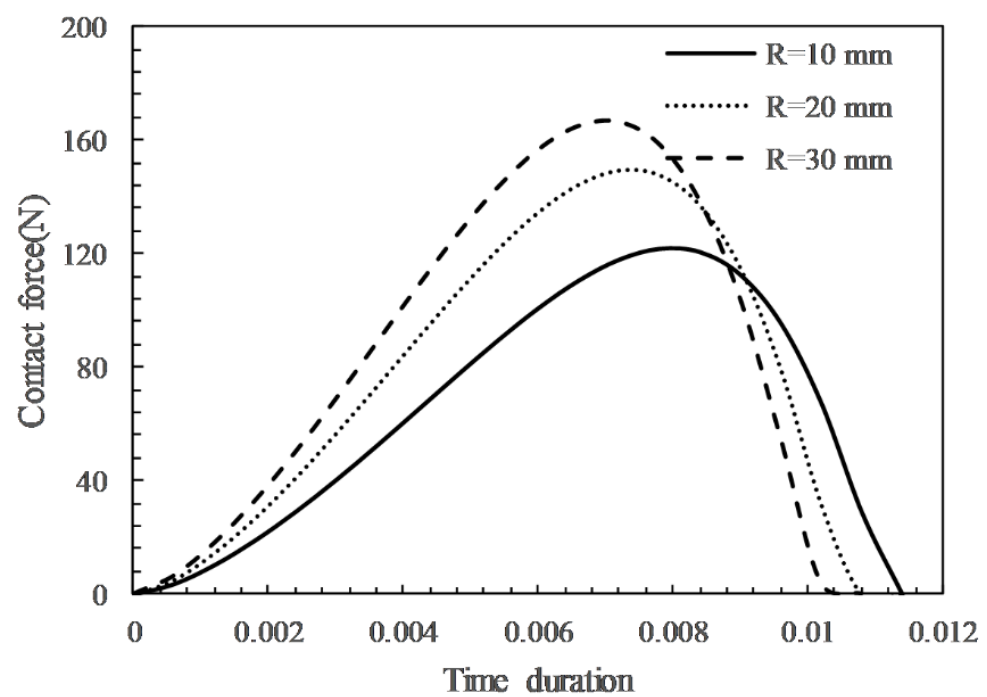

a)

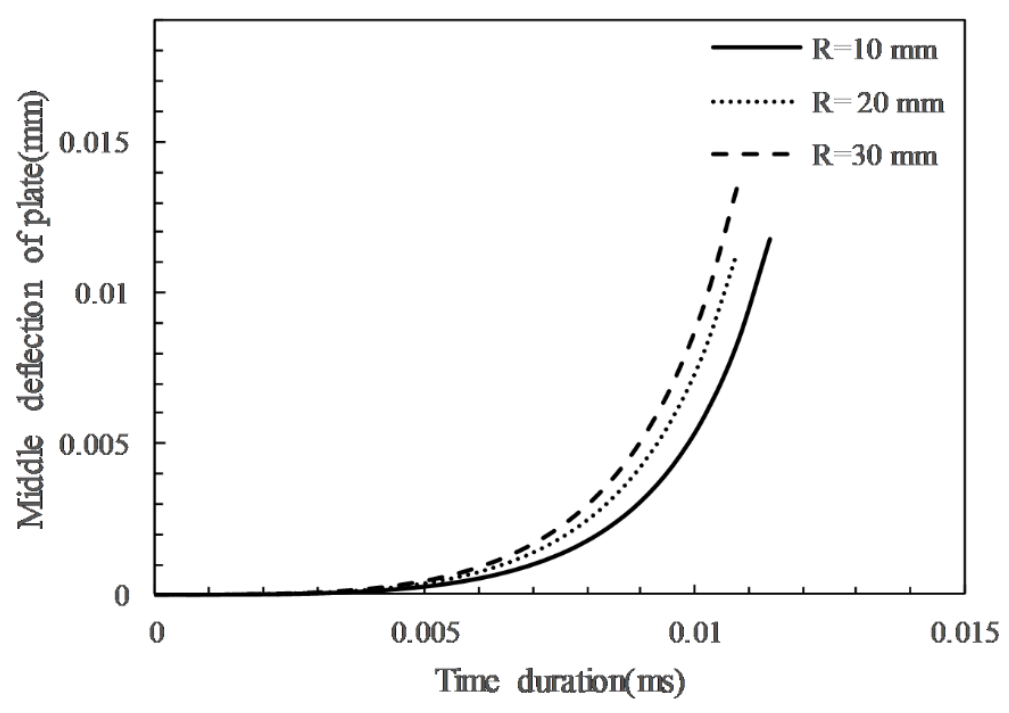

b)

Fig. 9 
a)

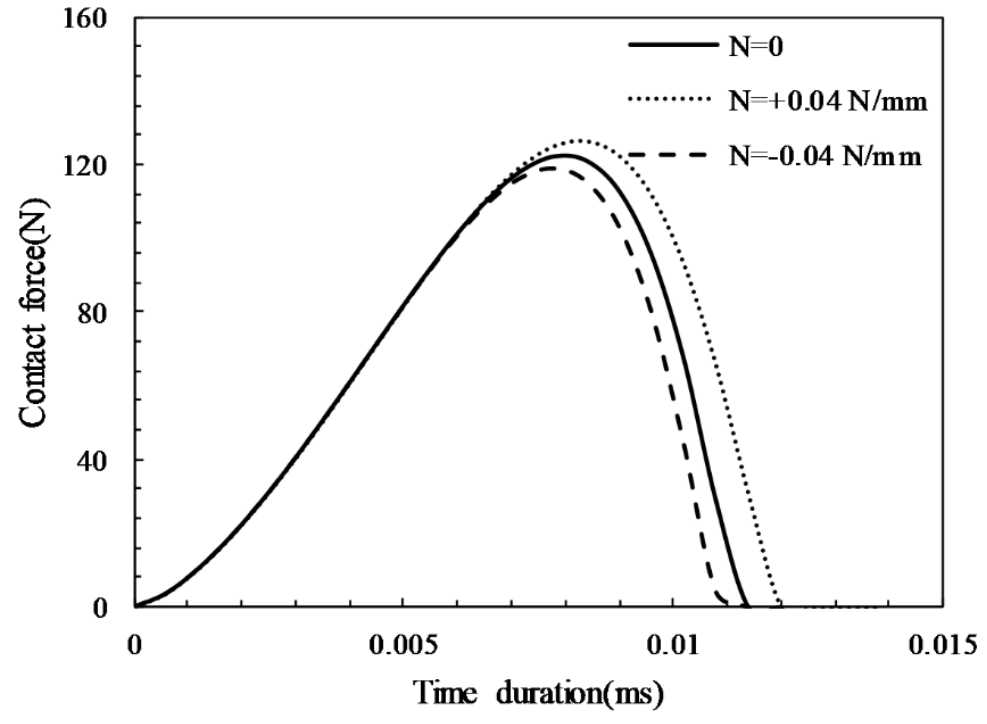

b)

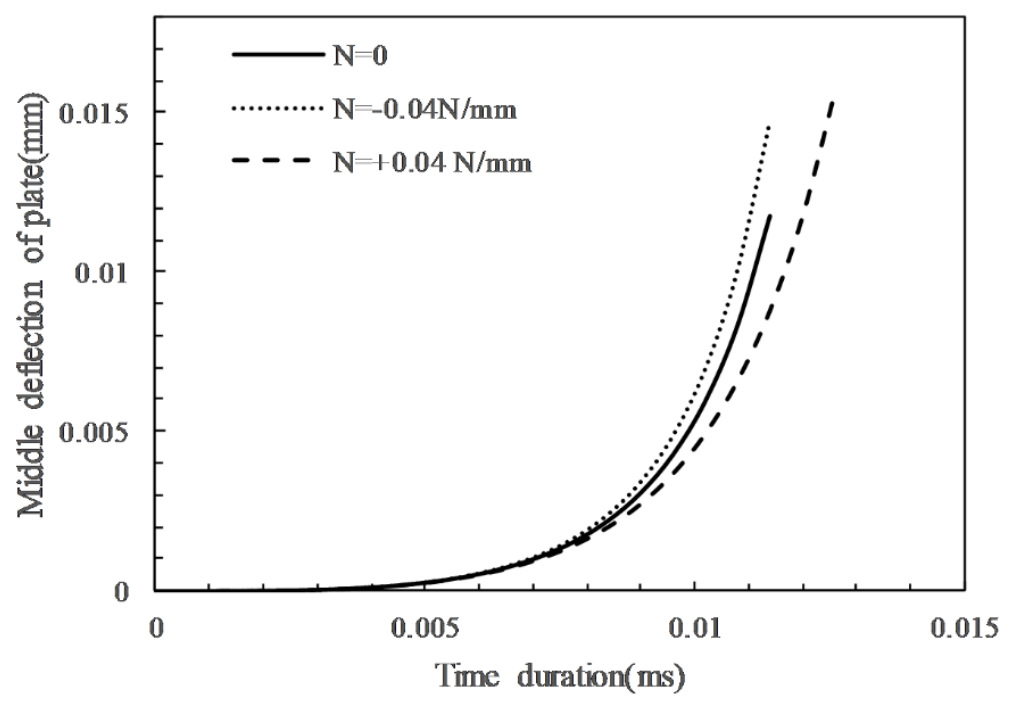

Fig. 10 


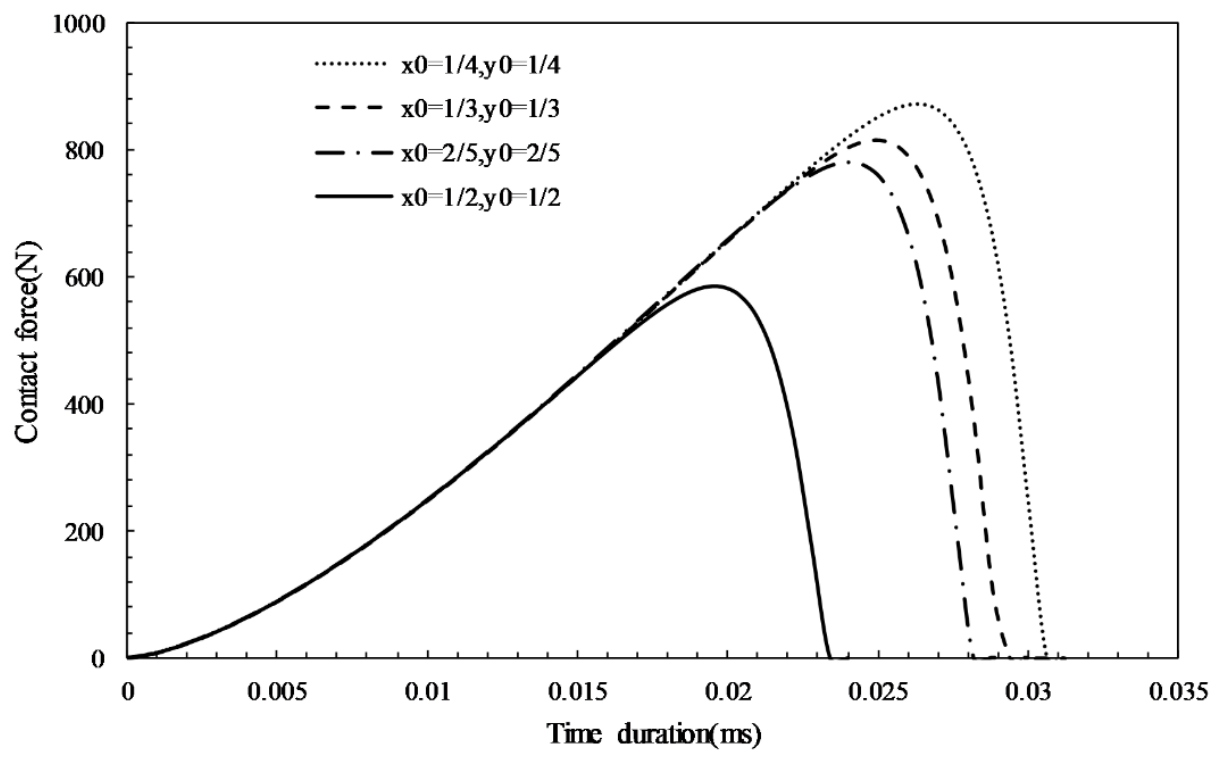

a)

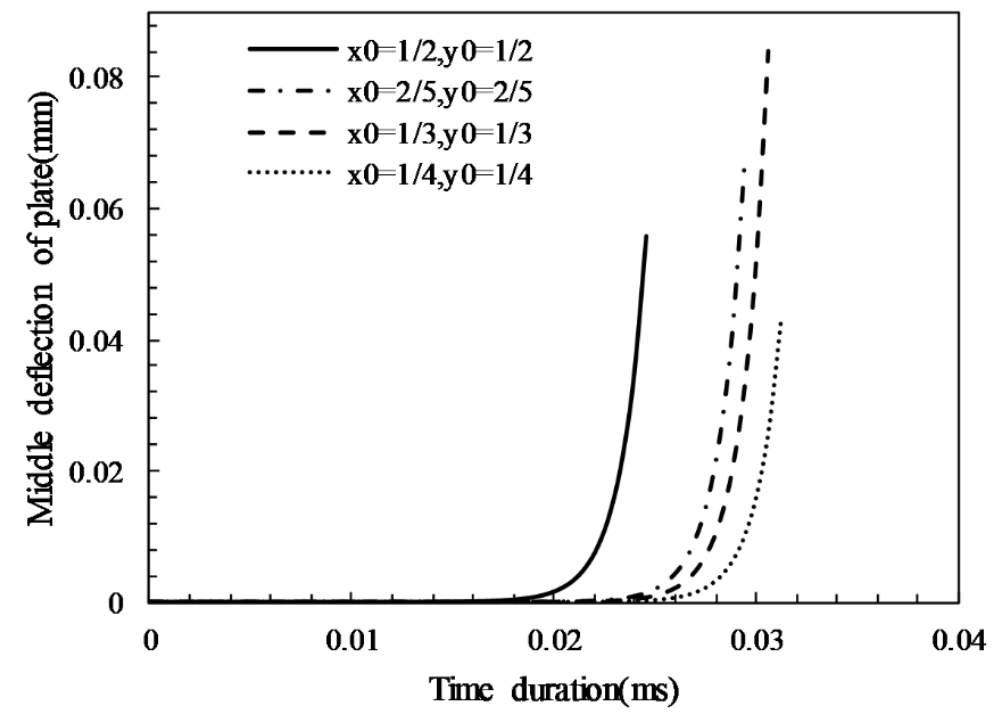

b)

Fig. 11 